Review

\title{
Sustainability assessment in circular inter-firm networks: An integrated framework of industrial ecology and circular supply chain management approaches
}

\author{
Anna M. Walker ${ }^{a}$, Walter J.V. Vermeulen ${ }^{\mathrm{b}}$, Alberto Simboli ${ }^{\mathrm{a}}$, Andrea Raggi ${ }^{\mathrm{a}}{ }^{\text {* }}$ \\ a Department of Economic Studies, University “G. D'Annunzio" - Pescara, Viale Pindaro 42, 65127, Pescara, Italy \\ ${ }^{\mathrm{b}}$ Copernicus Institute of Sustainable Development, Utrecht University, Heidelberglaan 2, 3584 CS, Utrecht, the Netherlands
}

\section{A R T I C L E I N F O}

\section{Article history:}

Received 17 April 2020

Received in revised form

28 October 2020

Accepted 5 December 2020

Available online 8 December 2020

Handling editor: Prof. Jiri Jaromir Klemeš

\section{Keywords:}

Industrial ecology

Sustainability assessment

Circular supply chain

Literature review

Inter-firm network

Circular economy

\begin{abstract}
A B S T R A C T
Circular economy has become a central concept of sustainable production and consumption since its introduction into the public eye. However, to ensure circular economy actually delivers on its promises regarding sustainability, it is vital to anticipate and assess the impact of circular economy practices in an integrated way. For that purpose, holistic assessments are crucial to enable transparent decision-making, clearly indicating possible trade-offs. While previous literature has mainly focused on product, company or country level, this paper contributes to an improved understanding of sustainability assessments on the inter-firm level. Given the vital role of inter-firm networks in the transition to a circular economy, the authors present a systematic literature review of sustainability assessment approaches applicable within circular inter-firm networks. These networks are primarily represented in two related fields relevant to circular economy: industrial ecology offers sustainability assessment approaches for inter- and intrasectoral business activities at different scales, whereas circular supply chain management is a promising source for sustainability assessment approaches considering product life cycles. Over 100 academic publications are reviewed and categorised according to assessment type, correspondence to the relevant field, and sustainability dimensions addressed. The results demonstrate that life cycle-based methodologies as well as indicator frameworks, often combined with multi-criteria decision-making methods, are the most common ex-post assessment approaches. Concurrently, the most frequent ex-ante assessments are based on mathematical programming. It is further observed that industrial ecology-related publications present more comprehensive environmental assessments, while circular supply chain management literature includes the social dimension more often, but superficially. Overall, the social dimension is least assessed and least integrated into the sustainability assessment. Based on the findings of the review, an integrated framework of approaches is developed, enabling decision-makers to identify suitable sustainability assessment approaches for circular inter-firm networks.
\end{abstract}

(C) 2020 Elsevier Ltd. All rights reserved.

\section{Contents}

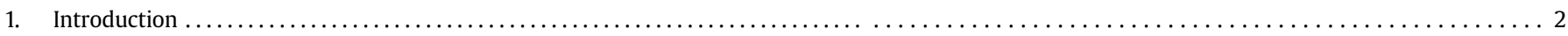

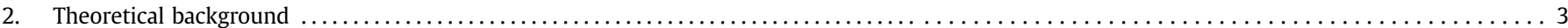

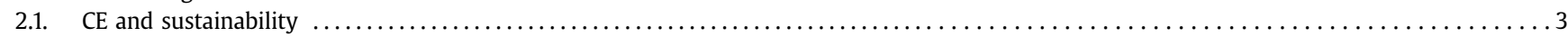

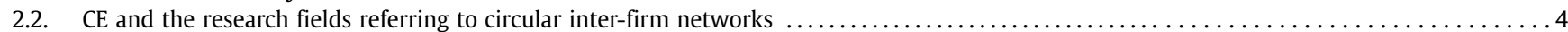

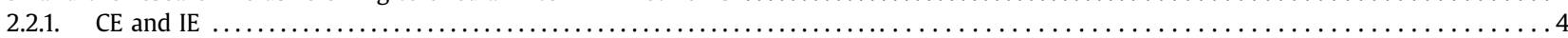

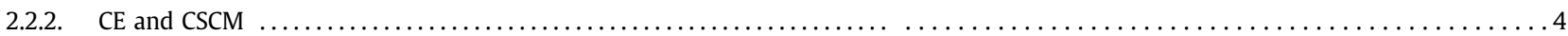

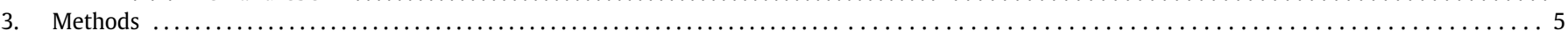

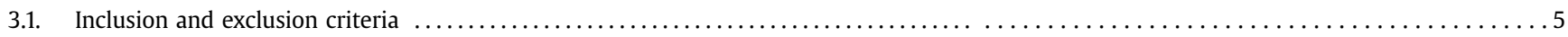

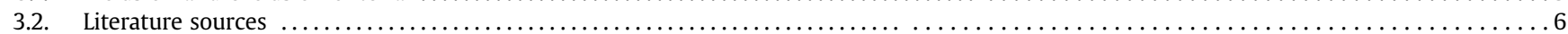

\footnotetext{
* Corresponding author.

E-mail address: a.raggi@unich.it (A. Raggi).
} 


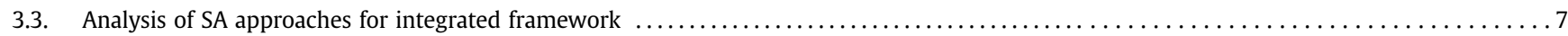

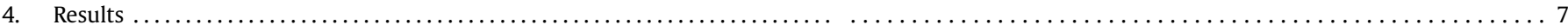

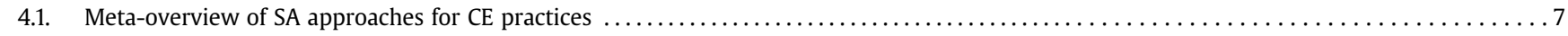

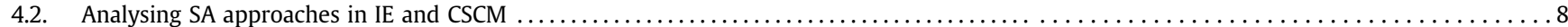

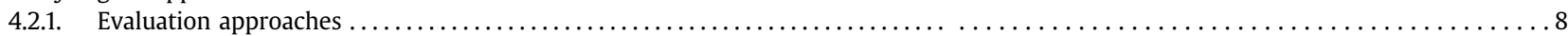

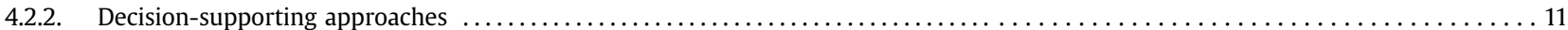

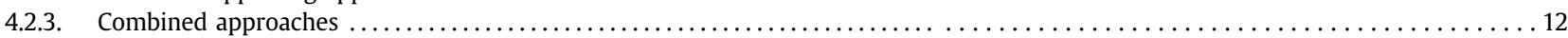

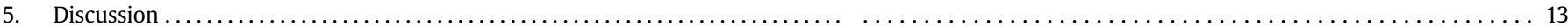

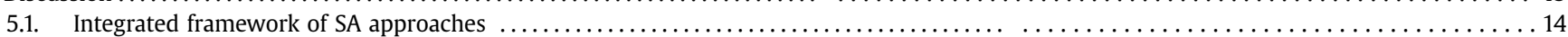

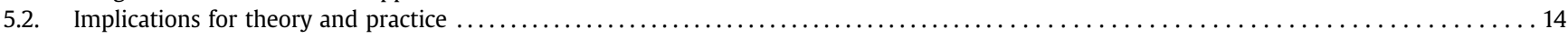

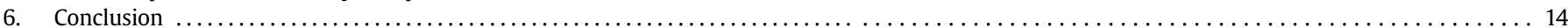

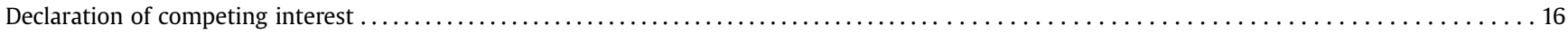

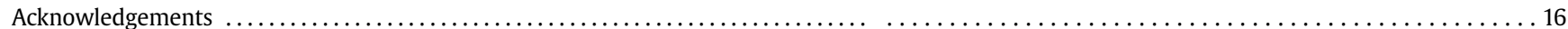

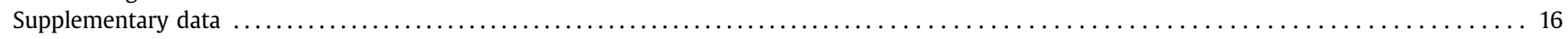

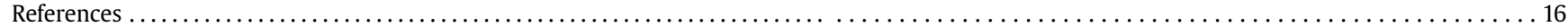

\begin{tabular}{|llll|}
\hline \multicolumn{2}{ll}{ List of abbreviations } & LCC & Life cycle costing \\
& & LCSA & Life cycle sustainability assessment \\
AHP & Analytic hierarchy process & LCT & Life cycle thinking \\
ANP & Analytic network process & MCDM & Multi-criteria decision-making \\
CE & Circular economy & MFA & Material flow analysis \\
CLSCM & Closed-loop supply chain management & MILP & Mixed integer linear programming \\
CSCM & Circular supply chain management & MINLP & Mixed integer non-linear programming \\
DEA & Data envelopment analysis & RL & Reverse logistics \\
EIO & Economic input-output & SA & Sustainability assessment \\
EIP & Eco-industrial park & SCM & Supply chain management \\
GRI & Global reporting initiative & SCOR & Supply chain operations reference \\
IE & Industrial ecology & SD & Sustainable development \\
IS & Industrial symbiosis & SFA & Substance flow analysis \\
LCA & Life cycle assessment & SLCA & Social life cycle assessment \\
& & & \\
\hline
\end{tabular}

\section{Introduction}

Though the circular economy (CE) has become a central paradigm of sustainable production and consumption (Ghisellini et al., 2016), actual positive sustainability implications of this shift remain to be scientifically established. While several scholars have reviewed CE measurement approaches which evaluate the circularity of products or the progress towards CE (Elia et al., 2017; Howard et al., 2019; Moraga et al., 2019; Saidani et al., 2019b), there is limited research focusing on whether CE actors and networks actually contribute to a sustainable society (Batista et al., 2018). Positive sustainability impacts of CE practices (i.e. circular business models, strategies and products solutions) have mostly been assumed and only recently been assessed, in the light of potential trade-offs between circularity and sustainability (Ghisellini et al., 2016). Systematic reviews of assessment approaches are provided by Kravchenko et al. (2019), who reviewed ex-ante indicators in the manufacturing sector with regards to the sustainability of circular initiatives, and Kristensen and Mosgaard (2020), who analysed micro-level circularity indicators and their relation to sustainability. Another metrics review is presented by Helander et al. (2019), who made an overview of the environmental impact of CE practices focusing on one dimension of sustainability. However, these articles only focus on indicator-based approaches. Meanwhile, Roos Lindgreen et al. (2020) made a more comprehensive analysis of assessment approaches for CE performance on a company-level, but limited their search to publications explicitly mentioning circularity, similarly to Corona et al. (2019), who included all assessment levels. There is thus a need for a comprehensive overview of sustainability assessment (SA) approaches which can be applied to CE practices. Furthermore, most of the previous reviews were focused on the company, product or country level, whereas the shift towards a CE is largely actuated by firms and their networks (Urbinati et al., 2017). Merely carrying out SAs of circular products or single companies adopting CE practices captures only part of the overall systemic sustainability impacts that CE practices generate. Hence, it is vital to extend the focus of the SA to a network of firms, operationalising their CE practices through the coordination of their production, distribution and recovery processes (Masi et al., 2017; Sehnem et al., 2019).

In search for suitable SA approaches, the authors refer to Homrich et al. (2018), who have identified two main CE research clusters. The first cluster is literature on industrial ecology (IE), particularly on industrial symbiosis (IS) and eco-industrial parks (EIPs), while the second covers research on supply chain management (SCM), especially circular supply chain management (CSCM). CSCM consists of a combination of sustainable, green and closedloop SCM and reverse logistics (CLSCM/RL) (Batista et al., 2018; Farooque et al., 2019; Masi et al., 2017). These two strands of research have dealt with SA approaches in inter-firm networks for decades. Several approaches to implement CE practices and assess their sustainability have been developed and practiced in the field 
of IE, which has had considerable influence on theorising and operationalising CE practices (Bruel et al., 2019; Saavedra et al., 2018). Similarly, sustainable SCM, green SCM and CLSCM/RL in particular, have dealt with SA approaches applicable to CE practices in inter-firm networks (Homrich et al., 2018; Stindt, 2017).

This paper proposes a systematic literature review according to Fink (2014), following the PRISMA criteria, to identify the main SA approaches used for inter-firm networks in IE and CSCM. These two fields analyse what the authors define as circular inter-firm networks. Sydow and Windeler (1998) define inter-firm networks "as an institutional arrangement among distinct but related for-profit organizations which is characterized by (1) a special kind of (network) relationship, (2) a certain degree of reflexivity, and (3) a logic of exchange that operates differently from that of markets and hierarchies" (p. 266). Building on this definition, circular inter-firm networks consist of actors that are connected through open (intersectoral) and/or closed (intrasectoral) supply chains which are de facto circular. This implies waste at the end-of-life of a product is reintroduced into the supply chain based on formalised or non-formalised relationships of the individual companies. While these circular inter-firm networks and related supply chain configurations have already been discussed in publications before 2015 , since the rising popularity of CE, they are specifically labelled by scholars (e.g. circular supply chains, IS for CE, or circular systems). Though the vocabulary may have changed, these do not often vary from supply chain configurations in circular inter-firm networks described in the past. Sehnem et al. (2019) and Masi et al. (2017) succinctly present the different research fields referring to circular inter-firm networks and the supply chain configurations applied, but, to the authors' knowledge, nobody has analysed their corresponding SA approaches yet. Reviews on the optimisation of sustainable supply chain designs (Eskandarpour et al., 2015; Moreno-Camacho et al., 2019) and EIPs (Boix et al., 2015), metrics for green and sustainable SCM (Ahi and Searcy, 2015a; Hassini et al., 2012), quantitative models for forward supply chains (Brandenburg et al., 2014; Brandenburg and Rebs, 2015), as well as decision-support tools and performance measurement for sustainable SCM (Taticchi et al., 2015) already hint towards a certain assessment toolset. However, despite their similarity, the SA approaches used in the IE and CSCM fields have to date not been integrated, and they are yet to be reviewed from a CE perspective with a focus on sustainability. This paper therefore aims to answer the following research question and sub-research questions:

RQ: What SA approaches from IE and CSCM are suitable for assessing CE practices in circular inter-firm networks?

SRQ1: What are the main SA approaches found in the literature for assessing CE practices in circular inter-firm networks?

SRQ2: How are the three sustainability dimensions assessed with these SA approaches?

Acknowledging the legacy of IE and CSCM, this review aims to identify suitable SA approaches for circular inter-firm networks from two diverse strands of academic literature and to compare them. The similarities and differences are then to be integrated into a SA framework applicable for circular inter-firm networks, depicting different methodologies, methods, models and indicator categories deemed useful. Such a SA toolset is critical to monitor a transition towards a CE that contributes to sustainable development (SD). The SAs to be analysed are both ex-ante and ex-post, covering the network design or planning stage and the evaluation stage of already implemented CE practices. This integrated framework shall provide initial guidance to sustainability professionals on the availability of SA approaches according to their company monitoring and reporting systems. From a theoretical perspective, the authors offer an overview of the current state-of-the-art SA approaches to assess CE practices on an inter-firm level, pointing out the main trends as well as the limitations in capturing the systemic nature of sustainability.

The paper is structured as follows. Section 2 presents the interlinkages of CE, sustainability, IE and CSCM, from which the search terms of the systematic review will be derived. The methods, including a review protocol and terminological considerations are introduced in Section 3. Section 4 presents the results of the comparative literature review, followed by a discussion in Section 5 , which leads to the integrated framework. The concluding section indicates future research avenues involving practitioners.

\section{Theoretical background}

The following two subsections are meant to briefly establish the base for the systematic literature review. The first discusses the conceptual links between CE and sustainability, while the second presents an overview of the overlap between CE, IE and CSCM. For a more detailed discussion on the conceptual interlinkages, refer to Walker et al. (2019).

\subsection{CE and sustainability}

As this article aims to shed light on the current practice of assessing the sustainability of CE practices from an academic perspective, it is essential to define what is meant by the concept of $\mathrm{CE}$ as well as sustainability. While the CE concept is rather recent, still fuzzy, and in large parts based on public and private practitioners (Calisto Friant et al., 2020; Korhonen et al., 2018), the concept of sustainability is more mature and well documented in academia (Geissdoerfer et al., 2017). In the plethora of proposed CE definitions, making a sole objective choice is hardly possible. Therefore, the authors have opted for a definition of Kirchherr et al. (2017), who have reviewed 114 CE definitions from scholars and subsequently contributed their own:

"A circular economy describes an economic system that is based on business models which replace the 'end-of-life' concept with reducing, alternatively reusing, recycling and recovering materials in production/distribution and consumption processes, thus operating at the micro level (products, companies, consumers), meso level (eco-industrial parks) and macro level (city, region, nation and beyond), with the aim to accomplish sustainable development, which implies creating environmental quality, economic prosperity and social equity, to the benefit of current and future generations" (p. 224).

Taking this consensus-based definition above as foundation of this analysis, the paper aims to identify (in the SRQ2) the extent to which contemporary assessment practices proposed in academia are consistent with it. In its current form, the wording seems to integrate the three main pillars of sustainability: the environment, the economy, and society. On top of that, the definition also considers intergenerational fairness, officially anchored in the most renown SD concept in the Brundtland Commission report (World Commission on Environment and Development, 1987). Commendably, this CE definition also mentions economic prosperity instead of "economic growth" or "profit", leading towards an understanding of sustainability where economic prosperity is mainly of service to "integral ecological and social fairness" (Vermeulen, 2018). For this paper, the concept of sustainability deviates from Elkington's (1998) frequently cited People, Planet and Profit trilogy in the private sector and follows the People, Planet and Prosperity triple-P advanced by the Sustainable Development Goals in the 
2030 Agenda for Sustainable Development (UN General Assembly, 2015). So, while profit may be essential to finance initiatives that foster integral ecological and social fairness, it is considered a means and not an end (Figuière and Rocca, 2008). In relation to this holistic understanding of SD, CE differs in two central aspects. First, while the beneficiaries of $\mathrm{CE}$ are mostly private sector actors, the whole society is meant to benefit from more SD (Geissdoerfer et al., 2017). This results in a different prioritisation of the three sustainability dimensions for $\mathrm{CE}$, which mainly aims at economic profitability through more efficient resource use and less environmental impacts (Garcés-Ayerbe et al., 2019). Second, social sustainability is merely indirectly linked to CE through job creation, for example (Geissdoerfer et al., 2017). This narrow conceptualisation of the social dimension has caused many scholars to reconsider the use of CE practices as a tool for SD (Calisto Friant et al., 2020; Saavedra et al., 2018; Suárez-Eiroa et al., 2019). Despite these potential shortcomings, Cecchin et al. (2020) have put forward the argument that $\mathrm{CE}$ presents one of the most actionable concepts towards SD.

Just as in the general SA, the SA related to CE faces the issue of integrating the three sustainability dimensions (Sala et al., 2013); even more so, given the social dimension is not clearly defined in CE (Murray et al., 2015). A SA is inherently complex, and its results often cannot be reduced to a single sustainability value (Gasparatos et al., 2009). Even within each of the three dimensions, Seager and Theis (2004) consider the aggregation into one single value to be an oversimplification, leading to a loss of information. However, given limited time and expertise, private and public actors usually prefer multifaceted information to be summarised into a single number to facilitate comparability (Barbiroli et al., 2006; Bocken et al., 2016). Then again, especially in ex-ante evaluations for purpose of (re) design and improvements of CE practices, a certain degree of detail is needed. Keeping this train of thought in mind, it is essential to meet academic claims to completeness with pragmatic evaluations on practicability when developing SA approaches.

\subsection{CE and the research fields referring to circular inter-firm networks}

Homrich et al. (2018) found that two research clusters currently dominate in CE; the IE cluster on the one hand, and the supply chain-oriented cluster on the other. These two strands of research are not yet well connected (Batista et al., 2018; Stindt, 2017) and hence, a first attempt to do so is presented here. The two clusters are expected to provide the main sources for the SA of CE practices for circular inter-firm networks. An overview of the definitions of the connected research fields and the different supply chain configurations applied within circular inter-firm networks is presented in Table 1.

\subsubsection{CE and IE}

Given that $\mathrm{CE}$ is a recent concept and thus assessment approaches for CE practices are limited, the CE definition is operationalised through well-researched approaches such as IS, developed in an IE context (Saavedra et al., 2018). A comparison of the IE and CE concepts shows significant overlap and substantiates the conceptual proximity (Cecchin et al., 2020). In recent years, these parallels have become even more obvious, as the effects of material flows on economic and social factors are now also considered part of IE (Kühnen and Hahn, 2017). Just as CE, IE is frequently being cited as a central tool to achieve SD (Ehrenfeld, 2007; Gibbs, 2009). Yet, the concepts differ in the perspective they take on the ideal organisation of material flows. While IE aims to modify production and consumption systems to imitate natural ecosystems (Frosch and Gallopoulos, 1989), the end-goal of the CE is a closed-loop economy with zero-waste, where products have a regenerative design (Murray et al., 2015; Sehnem et al., 2019). Even though the ideal states differ, the two concepts have similar ways to achieve these goals in practice. The most prominent operationalisation of IE on the inter-firm level in a geographically delimited area is IS in an EIP (Korhonen, 2002). Gibbs and Deutz (2007) found in their field studies that most EIPs do not assess the sustainability of their IS company linkages. When undertaken, however, such a SA requires increased attention on the contextualisation of (potential) impacts in a certain location, and therefore benefits from the inclusion of organisational and social aspects (Simboli et al., 2012). Meanwhile, IE can also take the form of a product-cycle, considering the environmental, economic and, more recently, the social impacts of the whole life cycle of a product (Boons and Baas, 1997; Kühnen and Hahn, 2017). The product-cycle perspective accounts for aggregated effects of the product life cycle, some of which might occur far away from the final production site during either the raw material extraction phase, the use-phase or the disposal of a product (Korhonen, 2002). In this respect, life cycle thinking (LCT) is the most frequently used assessment rationale (Boons and Howard-Grenville, 2009).

\subsubsection{CE and CSCM}

While IS is mostly implemented in organisational clusters in a locally delimited area - the size of the area can vary considerably -

Table 1

Definition of research fields referring to circular inter-firm networks and their supply chain configurations.

\begin{tabular}{|c|c|}
\hline $\log y$ (IE) is... & $\begin{array}{l}\text { "the field of the flows of materials and energy in industrial and consumer activities, of the effects of these flows on the environment, and } \\
\text { of the influences of economic, political, regulatory and social factors on the flow, use and transformation of resources" (White, 1994). }\end{array}$ \\
\hline Industrial symbiosis (IS). & $\begin{array}{l}\text { "engages traditionally separate entities in a collective approach to competitive advantage involving physical exchange of materials, } \\
\text { energy, water, and by-products. The keys to industrial symbiosis are collaboration and the synergistic possibilities offered by geographic } \\
\text { proximity" (Chertow, 2000, p. 314). }\end{array}$ \\
\hline An eco-industrial park (EIP) is... & $\begin{array}{l}\text { "a community of businesses that cooperate with each other and with the local community to efficiently share resources (information, } \\
\text { materials, water, energy, infrastructure and natural habitat), leading to economic gains, gains in environmental quality, and equitable } \\
\text { enhancement of human resources for the business and local community"(President's Council on Sustainable Development, 1997, p. 1, } \\
\text { cit. in Chertow, 2000)(Chertow, 2000) }\end{array}$ \\
\hline $\begin{array}{l}\text { Circular supply chain management } \\
\text { (CSCM) is... }\end{array}$ & $\begin{array}{l}\text { "the integration of circular thinking into the management of the supply chain and its surrounding industrial and natural ecosystems. It } \\
\text { systematically restores technical materials and regenerates biological materials toward a zero-waste vision through system-wide } \\
\text { innovation in business models and supply chain functions from product/service design to end-of-life and waste management, involving } \\
\text { all stakeholders in a product/service lifecycle including parts/product manufacturers, service providers, consumers, and users" } \\
\text { (Farooque et al., 2019, p. 884). }\end{array}$ \\
\hline $\begin{array}{l}\text { Closed-loop supply chain mai } \\
\quad(\text { CLSCM) is... }\end{array}$ & $\begin{array}{l}\text { "the design, control, and operation of a system to maximise value creation over the entire life cycle of a product with dynamic recover } \\
\text { of value from different types and volumes of returns over time" (Guide and Wassenhove, 2009). }\end{array}$ \\
\hline Reverse logistics is (RL)... & $\begin{array}{l}\text { "the process of planning, implementing, and controlling the efficient, cost effective flow of raw materials, in-process inventory, finished } \\
\text { goods and related information from the point of consumption to the point of origin for the purpose of recapturing value or proper } \\
\text { disposal" (Rogers and Tibben-Lembke, 1999). }\end{array}$ \\
\hline
\end{tabular}


Table 2

Review protocol (adapted from Tarne et al., 2017, p. 3).

\begin{tabular}{|c|c|}
\hline $\begin{array}{l}\text { Review } \\
\text { questions }\end{array}$ & $\begin{array}{l}\text { RQ: What SA approaches from IE and CSCM are suitable for assessing CE practices in circular inter-firm networks? } \\
\text { SRQ1: What are the main SA approaches found in the literature for assessing CE practices in circular inter-firm networks? } \\
\text { SRQ2: How are the three sustainability dimensions assessed with these SA approaches? }\end{array}$ \\
\hline $\begin{array}{l}\text { Selection } \\
\text { criteria }\end{array}$ & $\begin{array}{l}\text { Inclusion criteria } \\
\text { - Peer reviewed journal article/conference paper, or book } \\
\text { - topical on SA in circular inter-firm network } \\
\text { - applicable to at least one industry sector, not just specific product } \\
\text { - term sustainability used in the context of SD } \\
\text { - SA approach accounts for possibility of multiple life cycles } \\
\text { - must adhere to either of the conditions: } \\
\text { o mention circularity or circular economy OR } \\
\text { o include at least two sustainability dimensions (in case it focuses on IE, IS, green or sustainable SCM, CLSCM, or RL) } \\
\text { Exclusion criteria } \\
\text { - not in English } \\
\text { - book review or editorial } \\
\text { - SA approd on a specific product or material } \\
\text { - mainly addressing energy-related assessment methods, such as emergy and exergy approaches }\end{array}$ \\
\hline $\begin{array}{l}\text { Literature } \\
\text { search }\end{array}$ & 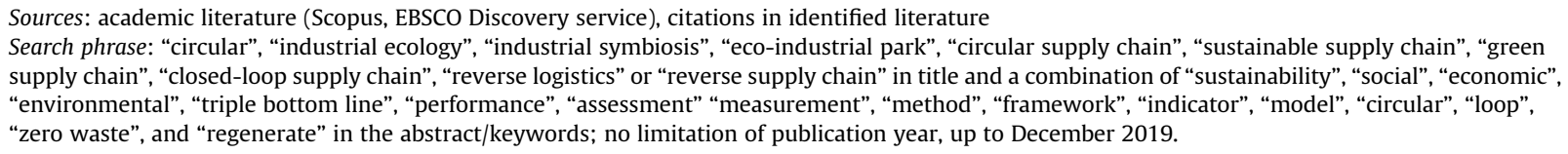 \\
\hline Evaluation & $\begin{array}{l}\text { Analysis of assessment approach, sustainability dimensions addressed, attribution to IE or CSCM, integration of social dimension, operationalisation of } \\
\text { economic dimension }\end{array}$ \\
\hline
\end{tabular}

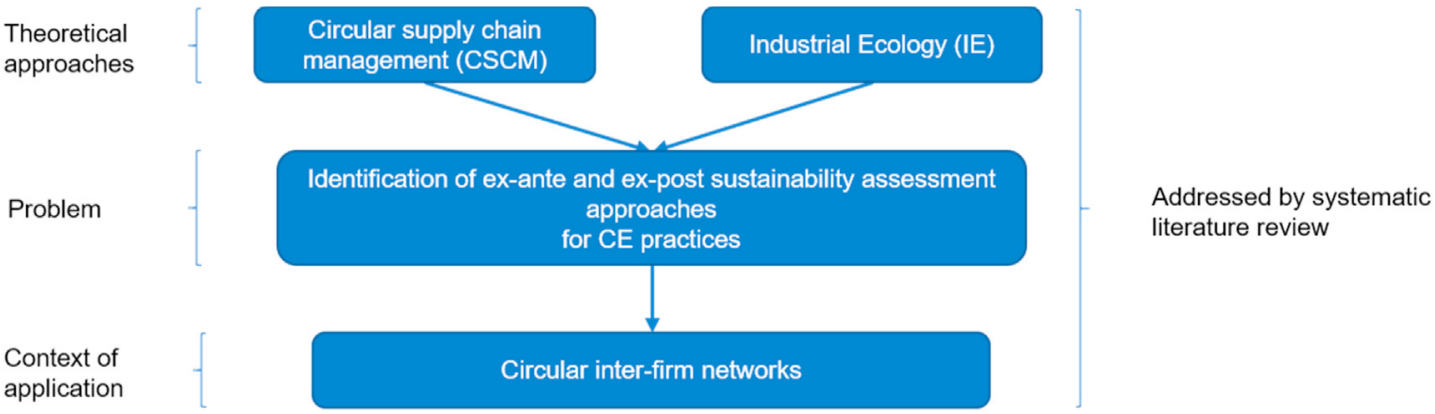

Fig. 1. Research design of literature review.

circular inter-firm networks often operate across several geographical locations. Therefore, CSCM provides an additional promising SA inventory. Farooque et al. (2019) essentially describe CSCM as a mix of sustainable, green and closed-loop SCM, with the overarching goal of creating zero waste. Importantly, it also includes open-loop supply chains, which represent the cascading material flows into other sectors (Batista et al., 2018). In case of geographical proximity, these open-loop supply chains can be assessed in the same way as IS. Additional assessment approaches considering sustainability from a product life cycle perspective are encompassed in the fields of CLSCM/RL. However, from their definitions in Table 1, no explicit social or environmental goals are apparent. Some argue closed-loop supply chains are intrinsically environmentally sustainable (Quariguasi Frota Neto et al., 2010), though disregarding the social dimension. In contrast, Govindan et al. (2015) see the need to close the research gap between CLSCM/RL and sustainability to obtain pertinent SA approaches.

Both Stindt (2017) as well as Govindan et al. (2015) underline the similarities of IS and CLSCM/RL and lay out well-established SA approaches mostly based on LCT. While Masi et al. (2017) and Sehnem et al. (2019) already connect EIPs, CLSCM, as well as green and sustainable SCM, this publication explicitly addresses SA approaches for circular inter-firm networks with a focus on SD (Homrich et al., 2018).

\section{Methods}

This part presents the review protocol in Table 2, following the PRISMA guidelines to ensure transparency of the research process (Fink, 2014). The protocol was adapted from the review of life cycle sustainability assessments (LCSAs) by Tarne et al. (2017). This format was chosen since the LCSA is viewed by multiple scholars to be the most comprehensive and operable SA framework (Sala et al., 2013) and "best at preventing burden shifting between stakeholders in the value chain" (Niero and Hauschild, 2017, p. 1). The overall research design is presented in Fig. 1.

\subsection{Inclusion and exclusion criteria}

The review question was developed against the background of applying $\mathrm{CE}$ as a tool to achieve SD, which means that approaches from IE and CSCM must also be considered. This was operationalised in the selection criteria depicted in Table 2 which ensured the selected publications address the assessment of sustainability aspects of CE practices within the fields of IE, IS, CSCM (split into green, sustainable and CLSCM), and RL. For circular inter-firm networks with supply chain configurations explicitly labelled as circular (e.g. IS for CE) the number of sustainability dimensions addressed in the SA approach was not a limiting factor. Meanwhile, 
the authors included publications on circular inter-firm networks with supply chain configurations which are not labelled as circular (e.g. merely IS) only if the SA addressed at least two sustainability dimensions simultaneously. Therefore, SA approaches addressing only one sustainability dimension were excluded, given that they have been thoroughly discussed in previous literature, and no additional insights on the integration of the different sustainability dimensions was to be expected. Furthermore, papers assessing circular inter-firm networks with supply chain configurations that are not explicitly labelled as circular were only included if they showed the SA could account for multiple product life cycles and cover the whole loop. This was checked by searching for the description of the SA scope of the inter-firm network in the text and graphics. Thus, for example papers on SA of sustainable SCM were excluded, if they only covered a single life cycle until the end-of-life of a product and did not foresee the re-entry of recovered material into the loop. Also, assessments related to exergy and emergy approaches were not included due to the missing environmental impact assessment, the difficulty to evaluate complex supply chains, and the lack of integration of the social perspective into the techno-ecological sphere (Marvuglia et al., 2018; ValenzuelaVenegas et al., 2016).

\subsection{Literature sources}

The review questions have been addressed with a systematic literature review of academic peer-reviewed publications available by December 2019. To maximise the coverage of research (Mongeon and Paul-Hus, 2016) the authors searched the academic database Scopus as well as EBSCO Discovery service, which includes the results of EBSCO host and Web of Science. In order to receive appropriate results, the main research fields and related supply chain configurations referring to circular inter-firm networks were searched in titles, while keywords related to assessment, sustainability and CE were included through abstract and keyword search. As visible in the research process flowchart in Fig. 2, the search string (available in the Appendix) resulted in a total of 651 hits on Scopus and 620 hits on EBSCO Discovery Service.

After a preliminary screening based on the title and an exclusion of the duplicates within the databases, there were 402 hits from Scopus and 395 from EBSCO Discovery Service left. Since some of the results overlapped, the authors eliminated the duplicates among the two databases and analysed 615 abstracts with special focus on the circular inter-firm network criterion. Thereafter, a full text screening of 262 publications ensured the exclusion of papers focusing on an incomplete or a single life cycle, the coverage of sustainability dimensions, as well as similar publications by the same authors. Moreover, five sources were not assessed due to restricted access. Of the remaining papers, 93 were found to be relevant for this review and another 19 were added through a cross-referencing approach, adding up to a total of 112 papers analysed according to the evaluation categories in Table 2.

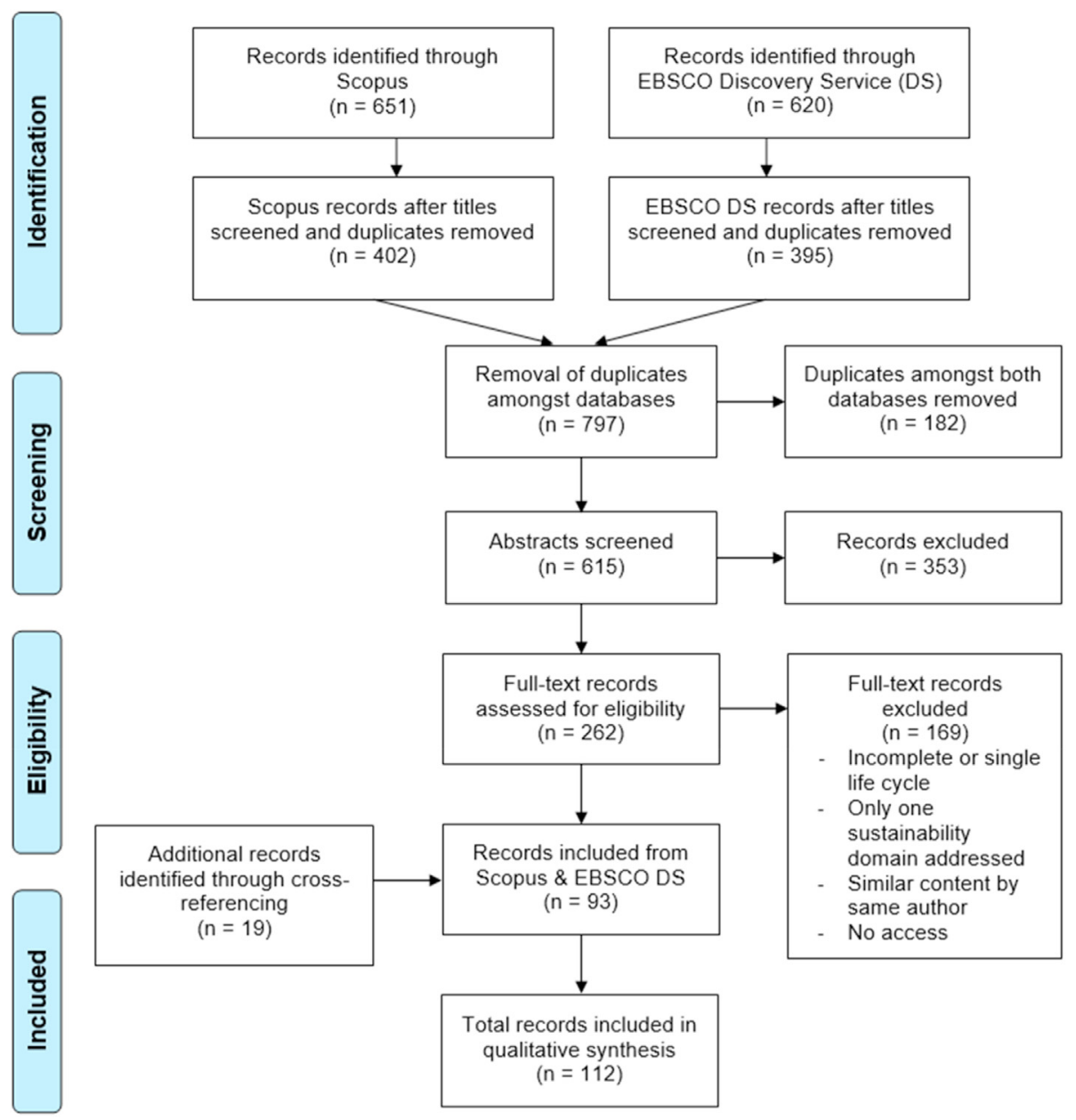

Fig. 2. PRISMA flowchart of research process (adapted from Moher et al., 2009). 


\subsection{Analysis of SA approaches for integrated framework}

The analysis of the SA approaches is structured into two main subdivisions, which are based on the overview of different evaluation and decision-supporting approaches for sustainable SCM by Stindt (2017), derived from Brandenburg et al. (2014) and Sasikumar and Kannan (2009). Stindt (2017) differentiates between two types of assessment. The first is the evaluation phase and includes evaluation methodologies such as the life cycle assessment (LCA), material flow analysis (MFA), eco-footprinting, social life cycle assessment (SLCA), social footprinting, criticality assessment, as well as auditing and surveys. The second phase is the decisionmaking phase, where different kinds of decision-supporting methodologies based on mathematical programming, simulation, multi-criteria decision-making (MCDM), artificial intelligence and analytical models are applied (Stindt, 2017). It needs to be emphasised that the borders between the evaluation and decisionmaking phase are blurry and overlapping at times. Therefore, the proposed categorisation presents only one of several ways to categorise the approaches. In Section 4.2, this categorisation will facilitate the presentation of SA approaches in the fields of IE and CSCM.

\section{Results}

In a first step, this section comparatively lays out overall quantitative trends emerging from the analysed literature. The publications from the field of IE are juxtaposed to those in the field of CSCM. Thereafter, the authors zoom in on the different evaluation and decision-supporting approaches and showcase potential SA approaches applicable to circular inter-firm networks.

\subsection{Meta-overview of SA approaches for CE practices}

Though CE has been discussed for more than a decade in Europe and even longer in China (Reike et al., 2018), the actual SA of CE practices in circular inter-firm networks has only been examined by scholars since 2013. This is visible in Fig. 3, which shows a sharp increase of publications on SAs for circular inter-firm networks, peaking in 2018 and 2019. It is also evident that most of the proposed approaches relate to CSCM. Contrary to what had been assumed by the authors, contributions mentioning IE approaches are also limited before 2013. The reason for this could be the exclusion criteria, requiring circular inter-firm networks not explicitly labelled as circular to address at least two sustainability dimensions to be included in this review.

The novelty of the topic is also depicted in the type of sources consulted. Even though most of the sources are academic journals, $13 \%$ are conference proceedings or journals publishing conference proceedings, known for presenting cutting edge results in emerging fields (Saidani et al., 2017). Looking at the sources in Fig. 4, the Journal of Cleaner Production is by far the most active with 23 publications, followed by the International Journal of Production Economics. While in the former journal the addressed research fields are distributed fairly equally, in the latter journal only the field of CSCM is covered. The journal Sustainability is in third place, trailed by Procedia CIRP, the Journal of Industrial Ecology, and the Annals of Operations Research, which are head-to-head.

As Fig. 5 shows, the three sustainability dimensions are unequally represented. Both the combination of only the environmental and economic pillars and the combination of all three sustainability pillars are assessed in 54 publications each. Concerning the economic dimension, caution of this interpretation is advised, since it is mostly defined in terms of costs and prices, thus not necessarily providing information on sustainability, but rather on profit and cost-effectiveness. When pairing the social and environmental dimension, there are only three publications. These findings substantiate the quest for increased research in the social dimension, which presents extra challenges when aggregating and weighing the three sustainability dimensions, as explained in Iacovidou et al. (2017b). Another interesting finding is that most of the publications that explicitly address the three sustainability dimensions are from the realm of CSCM, while in the other combinations, the distribution of the fields is nearly equal.

Concerning the number of publications, past country trends of publications were also confirmed (Ghisellini et al., 2016). Fig. 6 shows researchers in China, the overall leading country assessing CE practices regarding sustainability, mainly develop and analyse assessment approaches from an IE perspective, given the considerable number of EIPs in China. Coming second are authors within international collaborations, while the third place is taken by researchers from Iran, only publishing on CSCM, followed by Italy,

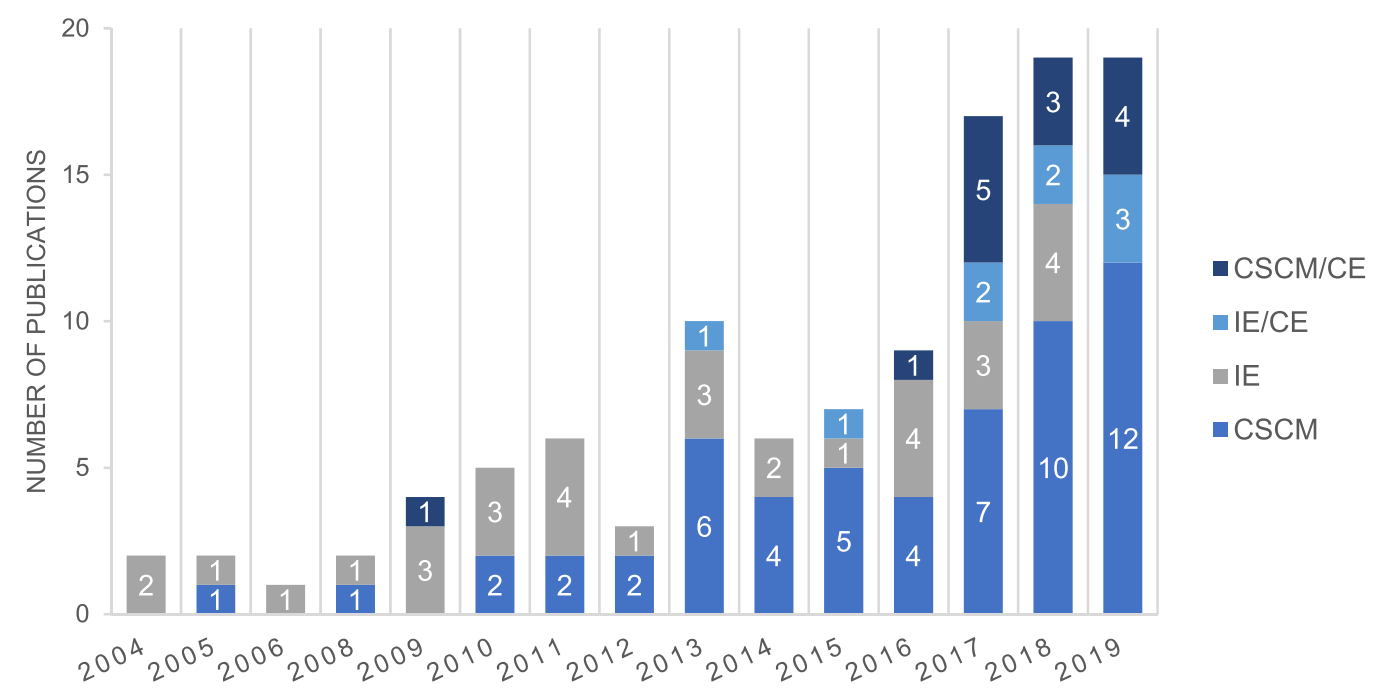

Fig. 3. Publications by year and field (own calculation). 


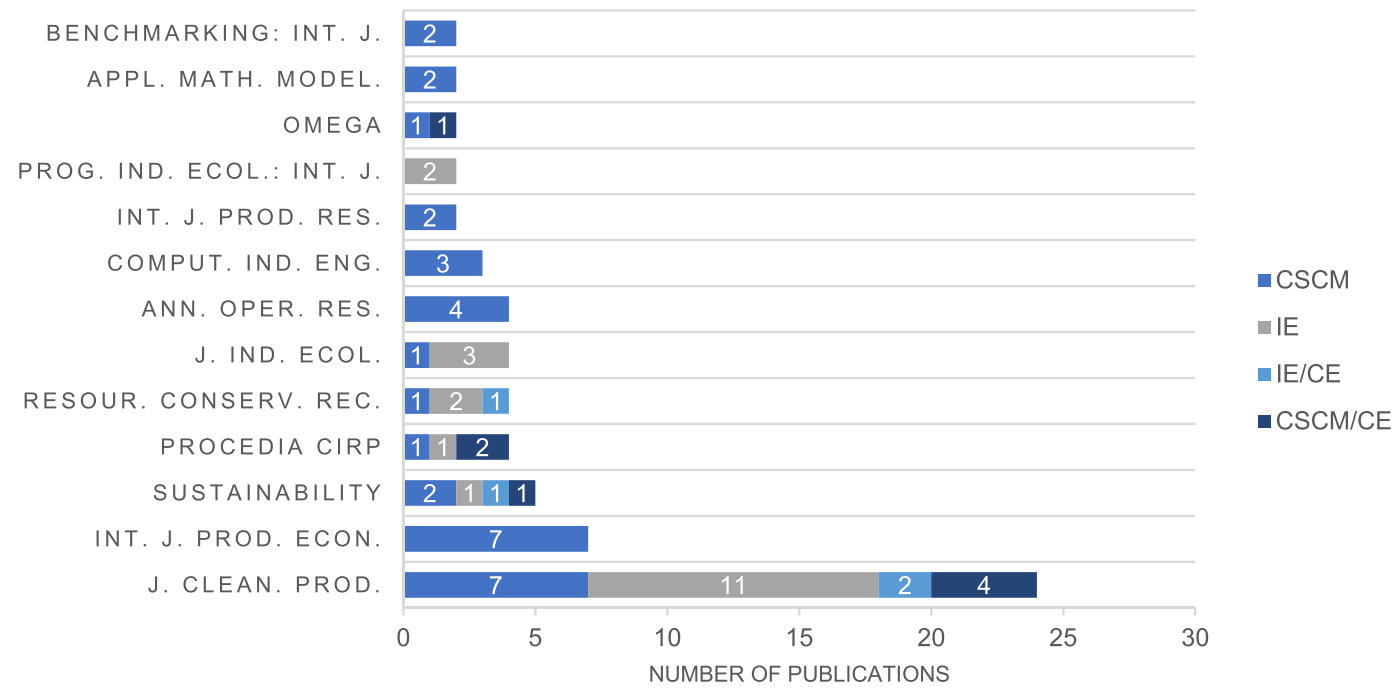

Fig. 4. Top 13 sources by field (own calculation).

and the US. Scholars from the UK, Canada, and India come mainly from a CSCM perspective. Finally, while Dutch researchers have been active in publishing on company-level indices (Kristensen and Mosgaard, 2020), their publications on the inter-firm level are limited.

Fig. 7 presents the distribution of subfields within the two main fields, CSCM and IE. In the CSCM field, most of the contributions by far are coming from CLSCM, followed by sustainable and green SCM. The main subfield in IE is IS. Overall, the field of CSCM has the most publications. Interestingly, most of the publications (78) also include a case study, showing that the SA approaches presented go beyond theoretical developments. Considering the higher number of CSCM publications, both fields have a similar share of case studies.

\subsection{Analysing SA approaches in IE and CSCM}

In this section, the analysis is divided into evaluation approaches, decision-supporting approaches, and combined approaches. Each of the subsections starts with a description of the SA approaches used in the IE field and end with the ones in the CSCM field. In addition, the subsections also give more insight into the coverage of the three sustainability dimensions and their weighting in the SA, which is summarised in Table 3.

\subsubsection{Evaluation approaches}

This subsection is dedicated to publications addressing only evaluation approaches, while Section 4.2.3 discusses combined approaches. Table 4 presents the publications of both IE and CSCM approaches by evaluation type.

IE-related approaches. Roughly half of the evaluation approaches stem from the IE field. A frequently used methodology to assess the environmental dimension is the LCA (Corona et al., 2019). Scholars applied this data intensive (Zhang et al., 2013) LCT-based methodology to carry out comparative assessments (comparative LCA) (Martin and Harris, 2018; Strazza et al., 2015), in combination with an input-output analysis (Ferrão et al., 2015), and scenario analysis (Ardente et al., 2010; Dong et al., 2017a). Martin and Harris (2018) added a semi-quantitative socio-economic assessment to their comparative LCA, but do not weigh the dimensions against each other. Two other well-established IE methodologies are the MFA, and input-output analysis (Corona et al., 2019). MFA is frequently used to assess material flows in EIPs (Dong et al., 2013; Tang and Li, 2010), and at times supported by scenario analysis to determine potential symbiotic material flows (Santos and Magrini, 2018). Besides the environmental impact, both Ferrão et al. (2015) and Santos and Magrini (2018) further consider the social impact in terms of job creation, though this qualitative assessment is integrated neither with the LCA nor the MFA. The MFA can be visualised in a Sankey diagram and has been used in connection with several sustainability indicators to highlight CE business opportunities (Bianchini et al., 2019). Input-output analysis is applied in the form of dynamic enterprise input-output modelling to assess the effects of IS on supply chains (Fraccascia and Yazan, 2018). Besides the LCA and MFA, Elia et al. (2017) also mention the substance flow analysis (SFA) as well as the ecological footprint in their taxonomy of CE indices and methodologies.

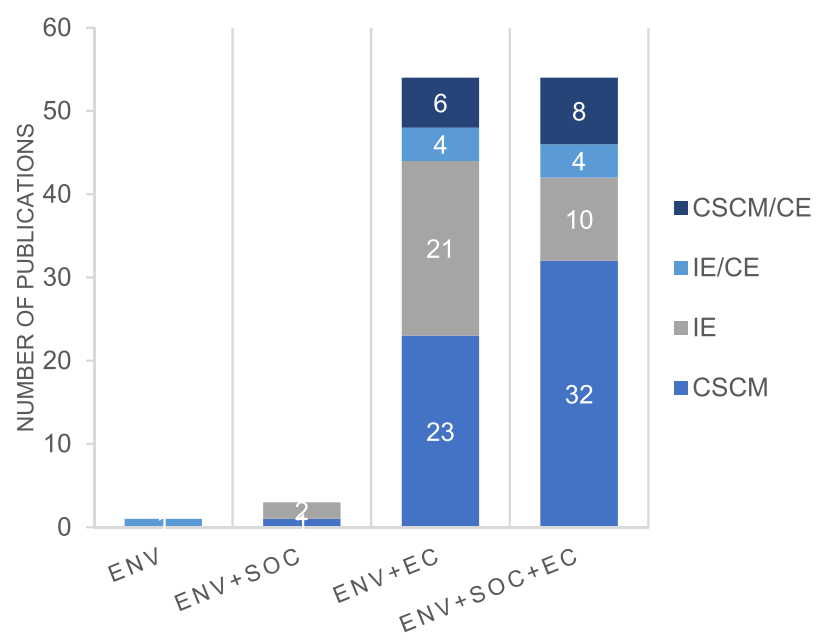

Fig. 5. Sustainability dimensions addressed by field (own calculation). 


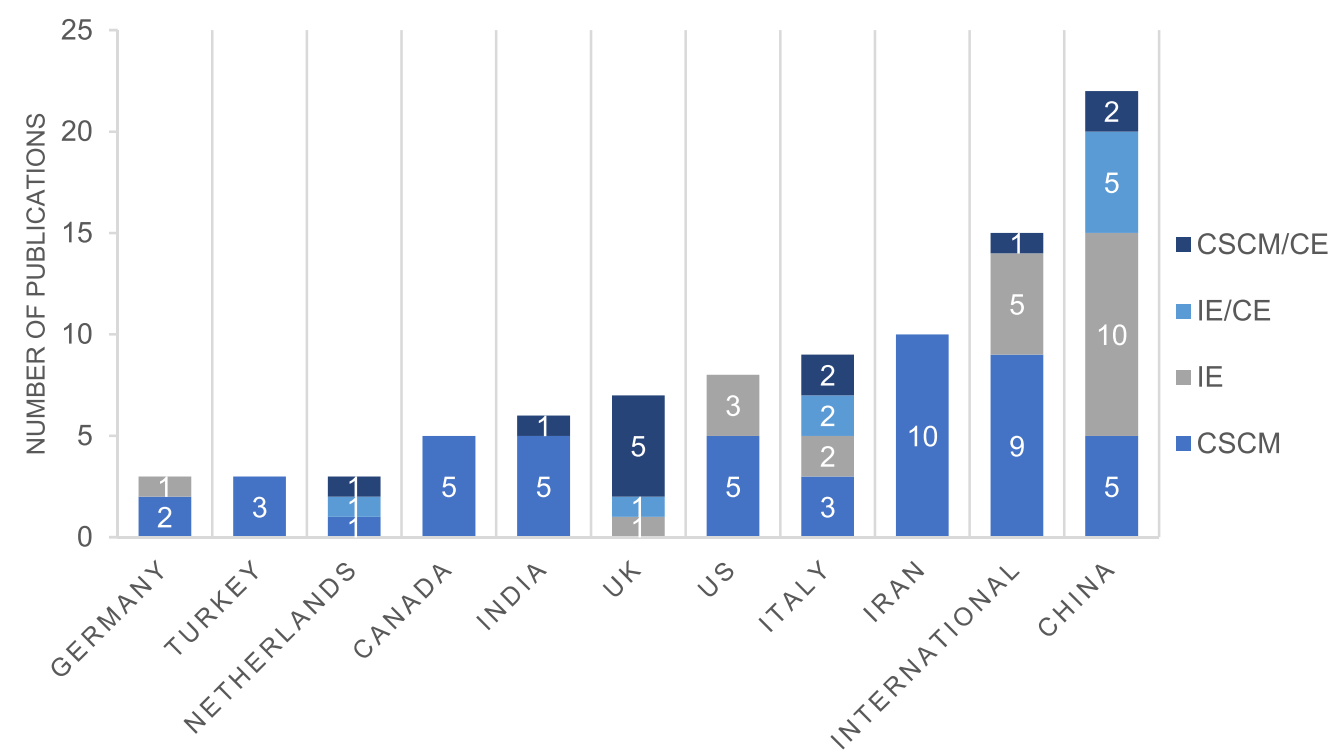

Fig. 6. Top 11 countries of authors by field (own calculation).

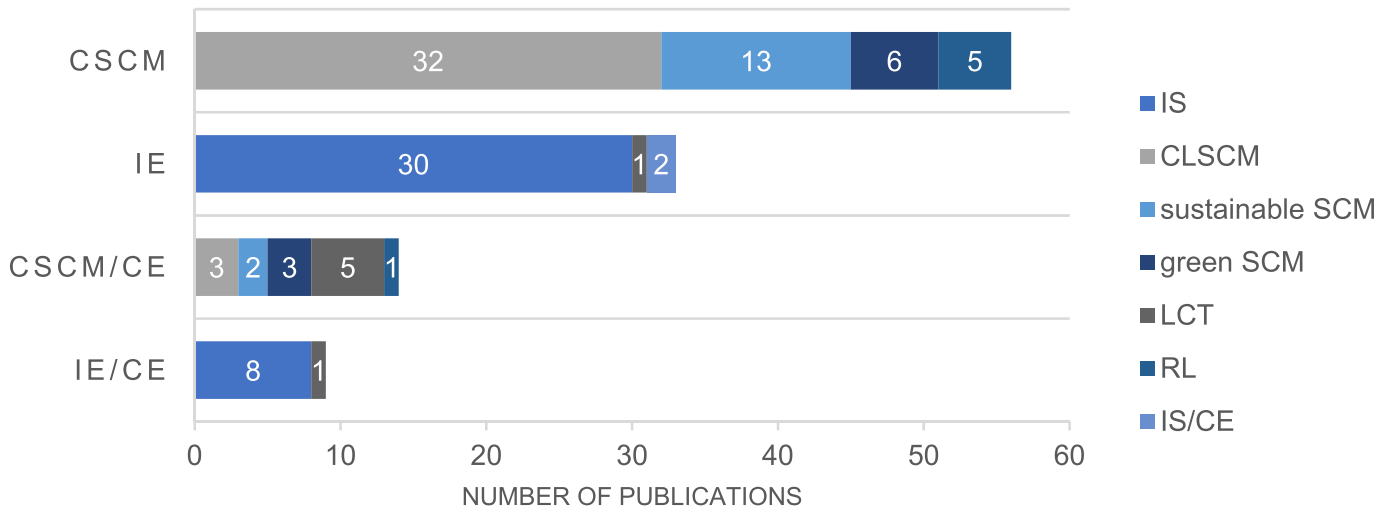

Fig. 7. Research fields and subfields (own calculation).

Another branch of evaluation approaches is based on indicators, which are used for creating indices and integrated frameworks. One example of indices are eco-efficiency indices, based on waste flows (An et al., 2011), or raw material flows (Park and Behera, 2014). Similarly, a resource productivity indicator was designed to capture waste data, combined with a SFA and two potential scenarios to assess an EIP (Wen and Meng, 2015). Jacobsen (2006) also uses waste and emission-related single indicators to determine the effects of different IS scenarios on the environmental and economic dimension. In contrast, Anand et al. (2019) developed the ecoleasing low-carbon effect comparison value, comparing the environmental and economic impacts of a closed-loop product service system for mobility with those of a linear production system. One of the most famous indicator sets is the Chinese National CE Indicator System for EIPs, which consists of non-weighted economic and environmental indicators (Geng et al., 2009, 2012), as well as the previously developed National Eco-Industrial Park Standard and the Green Park Evaluation Index System (Fu et al., 2019). Only one publication features a comprehensive review of sustainability indicators for EIPs, presenting four criteria (understanding, pragmatism, relevance, and partial representation) to guide the choice of scholars and practitioners selecting these indicators (ValenzuelaVenegas et al., 2016). On a more conceptual level, an interesting framework was derived from the Natural Step System Conditions, containing four conditions for the sustainability of human activities (Sokka et al., 2008). It was adapted to IS and proposes corresponding quantitative assessments, including LCT and mass balance methodologies. Pakarinen et al. (2010) apply this framework in a case study to identify suitable indicators, but the aggregation method of the indicators is not specified.

Regarding alternative evaluation methodologies, cost-benefit analyses including the economic and environmental perspective are suggested (Chertow and Lombardi, 2005; Xu et al., 2018). Moreover, Fons et al. (2004) propose fuzzy cognitive mapping combined with a sensitivity analysis to determine the economic benefits of symbiotic relationships, while not harming the environment.

CSCM-related approaches. LCT methodologies are also applied 
Table 3

Weighting of sustainability dimensions in SA approaches.

\begin{tabular}{|c|c|}
\hline Weighting of dimensions & References \\
\hline $\begin{array}{l}\text { Environmental and economic criteria equally } \\
\text { important }\end{array}$ & $\begin{array}{l}\text { An et al. (2011); Anand et al. (2019); Das and Rao Posinasetti (2015); Dong et al. (2017a); Fan et al. (2018); Gerber et al. } \\
\text { (2013); Jindal and Sangwan (2017); Govindan et al. (2017); Michelsen and Magerholm Fet (2010); Mohamed Abdul Ghani } \\
\text { et al. (2017); Jiao et al. (2018); Quariguasi Frota Neto et al. (2008); Park and Behera (2014); Wang and Gunasekaran } \\
\text { (2015); Wang et al. (2013); Yllmaz Balaman et al. (2018) }\end{array}$ \\
\hline $\begin{array}{l}\text { Economic criteria constrained by } \\
\text { environmental criteria }\end{array}$ & $\begin{array}{l}\text { Alkhayyal (2019); Chaabane et al. (2012); Cimren et al. (2011); Fahimnia et al. (2013); Mohajeri and Fallah (2016); Nidhi } \\
\text { and Pillai (2019); Xu et al. (2017) }\end{array}$ \\
\hline $\begin{array}{l}\text { Environmental, social and economic criteria } \\
\text { equally important }\end{array}$ & $\begin{array}{l}\text { Bal and Satoglu (2019); Bianchini et al. (2019); Brondi et al. (2018); Chardine-Baumann and Botta-Genoulaz (2014); } \\
\text { Devika et al. (2014); Hajiaghaei-Keshteli and Fard (2019); Mirmohammadi and Sahraeian (2018); Mota et al. (2018); } \\
\text { Nikolaou et al. (2013); Nobari and Kheirkhah (2018); Pishvaee et al. (2014); Pourjavad and Mayorga (2018); Pourjavad } \\
\text { and Mayorga (2019); Rezaei and Kheirkhah (2018); Sudarto et al. (2017); Taleizadeh et al. (2019); Tavakkoli Moghaddam } \\
\text { et al. (2019) }\end{array}$ \\
\hline $\begin{array}{l}\text { Economic most important, then } \\
\text { environmental and social criteria }\end{array}$ & $\begin{array}{l}\text { Fichtner et al. (2004); Kuznetsova et al. (2016); Metta and Badurdeen (2011); Modak et al. (2019); Nie (2016); Pakarinen } \\
\text { et al. (2010); Sarkar et al. (2017); Topi and Bilinska (2017) }\end{array}$ \\
\hline $\begin{array}{l}\text { Through MCDM method with expert } \\
\text { consultation }\end{array}$ & $\begin{array}{l}\text { Butzer et al. (2017); Hervani et al. (2005); Mubin (2016); Tseng et al. (2015); Xu (2009); Zhao et al. (2018); Zhao et al. } \\
\text { (2017); Zhou (2012) }\end{array}$ \\
\hline $\begin{array}{l}\text { Through MCDM method with stakeholder } \\
\text { consultation }\end{array}$ & Darbari et al. (2019); Ngan et al. (2019) \\
\hline Through expert consultation & Li (2013); Olugu et al. (2011); Trokanas et al. (2015) \\
\hline Through stakeholder consultation & Cervo et al. (2019); Iacovidou et al. (2017a); Kurup and Stehlik (2009) \\
\hline Through user of model & $\begin{array}{l}\text { Ahi et al. (2016); Ahi and Searcy (2015); Bottani and Casella (2018); Büyüközkan and Çifçi (2013); Fiksel and Bakshi } \\
\text { (2010); Fons et al. (2004); Jung et al. (2013); Kafa et al. (2013); Mehrjerdi and Lotfi (2019); Quariguasi Frota Neto et al. } \\
\text { (2010); Stindt et al. (2016); Wenbo (2011) }\end{array}$ \\
\hline Not weighted & $\begin{array}{l}\text { Asif et al. (2016); Ardente et al. (2010); Bressanelli et al. (2019); Chavez and Sharma (2018); Chertow and Lombardi } \\
\text { (2005); Corona et al. (2019); Cucchiella et al. (2014); Dong et al. (2013); Dong et al. (2017b); Elia et al. (2017); Ferrão et al. } \\
\text { (2015); Fraccascia and Yazan (2018); Fu et al. (2019); Geng et al. (2009); Geng et al. (2012); Genovese et al. (2017); Giurco } \\
\text { et al. (2011); Golroudbary and Zahraee (2015); Iacovidou et al. (2017b); Jacobsen (2006); Jain et al. (2018); Johari and } \\
\text { Hosseini-Motlagh (2019); Kazancoglu et al. (2018); Martin and Harris (2018); Niero and Hauschild (2017); Saidani et al. } \\
\text { (2019); Santos and Magrini (2018); Sgarbossa and Russo (2017); Sokka et al. (2008); Strazza et al. (2015); Tang and Li } \\
\text { (2010); Valenzuela-Venegas et al. (2016); Verstraeten-Jochemsen et al. (2018); Wen and Meng (2015); Xu et al. (2018); } \\
\text { Zhang et al. (2013) }\end{array}$ \\
\hline
\end{tabular}

Table 4

Evaluation approaches by type.

\begin{tabular}{|c|c|}
\hline Evaluation approaches & References $^{\mathrm{a}}$ \\
\hline LCT methodologies & $\begin{array}{l}\text { Ardente et al. (2010) }{ }^{\text {b }} \text {; Cucchiella et al. (2014); Corona et al. (2019) c ; Dong et al. (2017a) }{ }^{\text {b }} \text {; Elia et al. (2017); Fan et al. (2018) }{ }^{\text {b}} \text {; Ferrão } \\
\text { et al. (2015) }{ }^{\text {d }} \text {; Genovese et al. (2017) }{ }^{\text {; }} \text {; Martin and Harris (2018) }{ }^{\text {d }} \text {; Michelsen and Fet (2010) }{ }^{\text {b }} \text {; Niero and Hauschild (2017); Sokka et al. } \\
\text { (2008); Strazza et al. (2015); Verstraeten-Jochemsen et al. (2018); Zhang et al. (2013) }\end{array}$ \\
\hline $\begin{array}{l}\text { Mass-balance/ Input-output } \\
\text { analyses }\end{array}$ & $\begin{array}{l}\text { Bianchini et al. (2019); Dong et al. (2013); Elia et al. (2017); Fraccascia and Yazan (2018); Iacovidou et al. (2017b) }{ }^{\text {b; Jacobsen (2006) }}{ }^{\text {b; }} \\
\text { Saidani et al. (2019a); Santos and Magrini (2018) b; Sokka et al. (2008); Tang and Li (2010); Verstraeten-Jochemsen et al. (2018) }\end{array}$ \\
\hline Indicator frameworks & $\begin{array}{l}\text { Chardine-Baumann and Botta-Genoulaz (2014); Fu et al. (2019); Geng et al. (2009); Geng et al. (2012); Jain et al. (2018); Kafa et al. (2013); } \\
\text { Kazancoglu et al. (2018); Pakarinen et al. (2010); Sgarbossa and Russo (2017) c; Valenzuela-Venegas et al. (2016) }\end{array}$ \\
\hline Indices & An et al. (2011); Anand et al. (2019); Nikolaou et al. (2013); Park and Behera (2014); Wen and Meng (2015) b,c \\
\hline $\begin{array}{l}\text { Other evaluation } \\
\text { methodologies }\end{array}$ & $\begin{array}{l}\text { Bressanelli et al. (2019); Chertow and Lombardi (2005); Fons et al. (2004); Topi and Bilinska (2017) b; Verstraeten-Jochemsen et al. (2018); } \\
\text { Xu et al. (2018) }\end{array}$ \\
\hline
\end{tabular}

${ }^{a}$ In case authors propose separate approaches, they are mentioned in more than one field.

b Evaluation approach combined with scenario analysis.

c Evaluation approach combined with mass balance/input-output analysis.

d Evaluation approach combined with qualitative assessment.

in the field of CSCM in the form of a LCA and a life cycle costing (LCC) (Cucchiella et al., 2014), a comparative LCA (Fan et al., 2018), and a simplified ex-ante SA based on LCT (Bressanelli et al., 2019). These approaches are frequently complemented with scenario analysis to identify possible environmental and economic performance improvements (Bressanelli et al., 2019; Fan et al., 2018; Michelsen and Fet, 2010). Another integrated approach is the use of an LCSA connected with the Material Circularity Index by the Ellen MacArthur Foundation, potentially combined with MCDM methods (Niero and Hauschild, 2017). Genovese et al. (2017) present one of the first papers explicitly linking SCM to CE and combine a LCA with an environmentally extended multi-regional input-output (MRIO) model. Whereas mass-balance approaches are frequently applied by IE-based papers, only one publication in the CSCM field adopts an MFA approach (Saidani et al., 2019a) to assess the substance flows of valuable metals in Europe. Connecting many of the aforementioned approaches, a SA framework geared towards
Research and Development proposes three different types of evaluation depending on the maturity of the company (Verstraeten-Jochemsen et al., 2018). These include a circular quick scan of value retention-options, a MFA, an input-output analysis and a LCA for the environmental dimension, a cost-benefit analysis and a LCC for the economic dimension, and an expert opinion for the social dimension.

Coming to indices and indicator frameworks, Nikolaou et al. (2013) present the holistic Reverse Logistic Social Responsibility Performance Index; a combination of aggregated indicators, mainly based on the Global Reporting Initiative (GRI). A more generic indicator framework developed explicitly for circular supply chains is structured along the Supply-Chain-Operations-Reference-Model (SCOR) dimensions: plan, source, make, deliver and return (Jain et al., 2018). Similar to other integrated indicator frameworks destined for green SCM (Kafa et al., 2013; Kazancoglu et al., 2018), Jain et al. (2018) do not mention how to set the foreseen weights 
Table 5

Decision-supporting approaches by type.

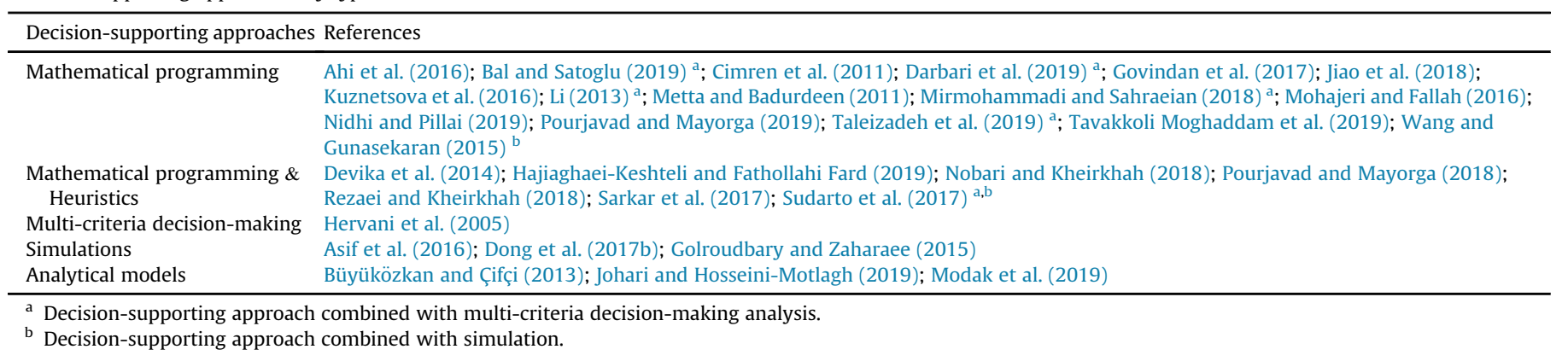

among the dimensions. One of the most frequently cited integrated indicator frameworks for sustainable SCM was introduced by Chardine-Baumann and Botta-Genoulaz (2014). They have developed a three-level analytical assessment model, adaptable to the maturity of the company, with indicators based on sustainability literature. The framework helps to identify the effects of sustainable SCM best practices on sustainability and indicates the trade-offs between the sustainability dimensions.

Simplified SAs consist of single indicators or cost calculations combined with qualitative social assessment, mainly focusing on job creation (Sgarbossa and Russo, 2017), and scenario analysis (Topi and Bilinska, 2017). A more intricate Complex Value Optimisation for Resource Recovery approach was developed based on a review of SA approaches for value recovery (Iacovidou et al., 2017b), combining a MFA with conceptual value assessment, scenario development, complex value assessment, an evaluation and reflection, as well as a potential final evaluation with MCDM methods for the waste sector (Iacovidou et al., 2017a). Iacovidou et al. (2017b) especially underline the importance of the social dimension for viability and accessibility of new CE practices.

\subsubsection{Decision-supporting approaches}

Within this paragraph, the publications in Table 5, addressing decision-supporting approaches, are discussed.

IE-related approaches. Starting again with IE, it becomes evident that this field has a lower representation than CSCM. Mathematical programming models have only been proposed in two cases. Cimren et al. (2011) describe a multi-integer programming model to optimise the material flow within by-product synergy networks and integrate it into the software tool Eco-Flow ${ }^{\mathrm{TM}}$ (discussed in Section 4.2.3) to analyse potential synergies. The second approach is an optimisation model for EIP design, taking into account the objectives of the individual actors in the objective function to determine the most economically sound and environmentally friendly design options (Kuznetsova et al., 2016). The final IE approach is presented by Dong et al. (2017b), who use system dynamics to establish the environmental and economic benefits of an EIP.

CSCM-related approaches. For the field of CSCM, the majority of decision-supporting approaches are based on mathematical programming. Ahi et al. (2016) developed a versatile stochastic framework, a derivative of Ahi and Searcy's (2015b) probabilistic optimisation model with their own sustainability indicators. In both cases, the authors leave the weighting of the three dimensions up to decision-makers. All three sustainability dimensions are also addressed in a mixed integer linear programming (MILP) model (Nidhi and Pillai, 2019) and a fuzzy multi-objective integer linear programming model (Pourjavad and Mayorga, 2019). While these two papers seek to minimise costs and environmental effects (mainly $\mathrm{CO}_{2}$ emissions) and maximise positive social impacts (mainly jobs created) simultaneously, Metta and Badurdeen (2011) developed a hierarchical MILP model, where the most important objective is the economic one, followed by the environmental and social one in this order. In contrast, some (fuzzy) optimisation models only consider the environmental and economic objectives (Jiao et al., 2018; Mohajeri and Fallah, 2016; Tavakkoli Moghaddam et al., 2019), while one paper adds the analytical hierarchy process (AHP) method for supplier selection to the MILP (Govindan et al., 2017).

Besides these purely mathematical programming approaches, several papers presented a mix of decision-supporting approaches. Darbari et al. (2019) started out with the AHP-TOPSIS method to determine the sustainability criteria relevant to stakeholders and then use the MILP with weighted fuzzy goal programming to optimise for the objectives identified through the MCDM method. In contrast, the results of a mixed integer non-linear programming (MINLP) model (Mirmohammadi and Sahraeian, 2018) and a MILP (Taleizadeh et al., 2019) have three objectives according to which they optimise first, and only in a second step do they employ the TOPSIS method and fuzzy AHP method respectively to identify the best option of the Pareto-optimal results. Another approach to evaluate Pareto-optimal solutions is the data envelopment analysis (DEA) method (Bal and Satoglu, 2019). On top of AHP and DEA, Hervani et al. (2005) propose the use of the balanced scorecard amongst other methodologies, such as ISO 14031, and the ECOSCAN tool to assess the environmental performance of green SCM. Besides these more renown MCDM methods, an alternative option is to complement the optimisation model with market data and expert advice for weighting of the environmental (referring only to recycling), economic and quality indicators (Li, 2013). Another frequent combination is mathematical programming models and heuristic approaches, such as algorithms. While models are based on MILP (Devika et al., 2014; Nobari and Kheirkhah, 2018; Rezaei and Kheirkhah, 2018), MINLP (Hajiaghaei-Keshteli and Fathollahi Fard, 2019; Sarkar et al., 2017), and fuzzy multi-objective integer linear programming (Pourjavad and Mayorga, 2018), they are all solved with algorithms to minimise costs and negative social and environmental impacts. In one case, the MILP and the algorithm are also combined with a system dynamics model (Sudarto et al., 2017), while in another, the mathematical model, optimising environmental and economic costs, uses a system dynamics approach to anticipate environmental effects (Wang and Gunasekaran, 2015).

Considering simulation, one pure system dynamics approach takes into consideration both customer satisfaction and the socalled green image factor (Golroudbary and Zaharaee, 2015). An additional option in this same category is a multi-method simulation tool with the aim to determine the ecological and environmental performance during multiple product life cycles (Asif et al., 2016).

In terms of analytical models, the Stackelberg game is applied in 
Table 6

Combinations of evaluation and decision-supporting approaches.

\begin{tabular}{|c|c|c|c|c|}
\hline $\begin{array}{l}\text { Decision- } \\
\text { support } \rightarrow \\
\text { Evaluation } \downarrow\end{array}$ & Mathematical programming & $\begin{array}{l}\text { Mathematical } \\
\text { programming \& } \\
\text { Heuristics }\end{array}$ & Multi-criteria decision making & Analytical models \\
\hline $\begin{array}{l}\text { LCT } \\
\text { methodologies }\end{array}$ & $\begin{array}{l}\text { Alkhayyal (2019); Chaabane et al. (2012); Das and Rao } \\
\text { Posinasetti (2015); Fichtner et al. (2004); Fiksel and Bakshi } \\
\text { (2010); Gerber et al. (2013); Jindal and Sangwan (2017); } \\
\text { Mehrjerdi and Lotfi (2019) b; Mohamed Abdul Ghani et al. } \\
\text { (2017); Mota et al. (2018); Quariguasi Frota Neto et al. (2008) } \\
\text { a,b; Quariguasi Frota Neto et al. (2010) }{ }^{\text {a }}\end{array}$ & $\begin{array}{l}\text { Brondi et al. } \\
\text { (2018); } \\
\text { Pishvaee et al. } \\
(2014)^{\text {a }}\end{array}$ & & Cervo et al. (2019) \\
\hline $\begin{array}{l}\text { Mass-balance/ } \\
\text { Input-output } \\
\text { analyses }\end{array}$ & Xu et al. $(2017)^{c}$ & & & \\
\hline $\begin{array}{l}\text { Indicator } \\
\text { frameworks }\end{array}$ & Ahi and Searcy (2015b) & & $\begin{array}{l}\text { Butzer et al. (2017); Mubin (2016) }{ }^{\text {c}} \text {; Ngan } \\
\text { et al. (2019); Nie (2016); Tseng et al. } \\
\text { (2015); Zhao et al. (2017); Zhao et al. } \\
\text { (2018); Zhou (2012) }\end{array}$ & $\begin{array}{l}\text { Jung et al. (2013); Kurup } \\
\text { and Stehlik (2009); Olugu } \\
\text { et al. (2011); Trokanas } \\
\text { et al. (2015) }\end{array}$ \\
\hline Indices & & & Wenbo (2011); Xu (2009) & \\
\hline $\begin{array}{l}\text { Other evaluation } \\
\text { methodologies }\end{array}$ & $\begin{array}{l}\text { Bottani and Casella (2018) }{ }^{\text {a,c }} \text {; Fahimnia et al. (2013); Wang } \\
\text { et al. (2013); Yılmaz Balaman et al. (2018) }\end{array}$ & & & $\begin{array}{l}\text { Chavez and Sharma } \\
\text { (2018); Giurco et al. } \\
\text { (2011) }\end{array}$ \\
\hline
\end{tabular}

${ }^{a}$ Decision-supporting approach combined with multi-criteria decision-making method.

b Decision-supporting approach combined with scenario analysis.

c Decision-supporting approach combined with simulation.

two cases and considers all three sustainability dimensions, though the main aim remains profit (Johari and Hosseini-Motlagh, 2019; Modak et al., 2019). A more quantitative approach prioritises customer needs based on group decision-making processes structured according to fuzzy set theory (Büyüközkan and Çifçi, 2013). The final approach presented in this paragraph does not fall into one of the categories set by Stindt's (2017) overview, but is rather a precursor for choosing a suitable decision-supporting approach to frame a problem. Stindt et al. (2016) present a transdisciplinary modelling framework, which helps create a verbal model of the supply chain system at hand. This ensures the viability and usefulness of the mathematical model developed in subsequent stages. To reach consensus on the model, stakeholders should go through the process of 1) defining key concepts and convergence of paradigms, 2) framing and scoping, 3) identifying relevant activities, 4) identifying inter-activity relationships, and finally, 5) identifying relevant information and decisions.

\subsubsection{Combined approaches}

Within this paragraph, the articles presented describe both evaluation and decision-supporting approaches. Here, IE and CSCM-related publications are more balanced than in the previous Section 4.2.2. An overview of the different combinations of approaches is presented in Table 6.

IE-related approaches. In the field of IE, mathematical programming models such as multi-objective MINLP models (Gerber et al., 2013) or MILP models (Fichtner et al., 2004; Fiksel and Bakshi, 2010) are combined with life cycle inventory databases and complemented with a visualisation tool called Eco-Flow ${ }^{\mathrm{TM}}$, to design and optimise IS or EIPs. In the former model (Gerber et al., 2013), both economic and environmental impacts have equal weight, whereas the main objective of the model by Fichtner et al. (2004) is profit maximisation, and the goal of the optimisation in the Eco-Flow ${ }^{\mathrm{TM}}$ tool is left to users (Fiksel and Bakshi, 2010). In addition to the economic and environmental dimension, another tool called Symby-Net, also includes the social one (Brondi et al., 2018). As in the previous approaches, the inputs of the LCA, LCC and SLCA are used as optimisation values for a multi-objective problem, using a heuristic approach, under different IS scenarios. An integrated approach without LCT is based on system dynamics as well as input-output modelling as a foundation of a fuzzy multi- objective programming model (Xu et al., 2017). While cost minimisation is the main objective, energy efficiency and minimal environmental impacts are sub-objectives.

Weighted indices and indicator frameworks are created with MCDM methods such as the grey Delphi method, the best-worst method (Zhao et al., 2018), entropy-weight method, and superiority linguistic ratings (Zhao et al., 2017) and AHP (Mubin, 2016). Mubin (2016) applies the AHP to unspecified sustainability indicators derived from the Labuschagne model, creates three IS scenarios, and depicts them in a traffic light system, in combination with a sustainability balanced scorecard. In yet another method, the CE performance evaluation index system for EIPs, indicators are weighted by the analytical network process (ANP) (Wenbo, 2011).

Moving away from MCDM methods, Jung et al. (2013) apply the discounted cash flow to assess the economic dimension and a multi-attribute global inference of quality (MAGIQ) method to rank indicators within the social and environmental dimension of an EIP. Another way to weigh (cost-based) indicator frameworks was expert consultation (Trokanas et al., 2015). Instead of experts, Kurup and Stehlik (2009) consulted stakeholders for indicator weighting of their six capitals model to assess IS. In a similar vein, an assessment framework called EPOS for planning IS foresees stakeholder consultation on top of a cost-benefit analysis, an LCA and social indicators, and revisits the identified IS opportunities though a LESTS (Legal, Economic, Spatial, Technical, and Social) analysis with surveys (Cervo et al., 2019). Both Kurup and Stehlik (2009) and Cervo et al. (2019) are among the few authors who include an extensive list of social indicators. Closing off the IE section is the backcasting approach, which entails the envisioning of different future scenarios for sustainable IS (Giurco et al., 2011). To assess the IS scenarios' impacts, a semi-quantitative energy and water impact assessment as well as a qualitative assessment of technical, socio-political and economic challenges were conducted.

CSCM-related approaches. In the field of CSCM, scholars have combined (fuzzy, multi-objective) MILP models (Jindal and Sangwan, 2017; Mehrjerdi and Lotfi, 2019; Mota et al., 2018; Pishvaee et al., 2014; Quariguasi Frota Neto et al., 2008) and multiobjective linear programming models (Chaabane et al., 2012; Das and Rao Posinasetti, 2015; Quariguasi Frota Neto et al., 2010) with the results of LCT methodologies. Most of the models have two objectives, (i.e. the simultaneous optimisation of the economic and 
environmental dimension) while some (Chabaane et al., 2012; Mehrjerdi and Lotfi, 2019; Mota et al., 2018; Pishvaee et al., 2014) also take into account the social dimension. The weights within and amongst the different dimension are often pre-set, but some models leave it up to the user (Mehrjerdi and Lotfi, 2019), use AHP (Pishvaee et al., 2014), or a DEA-inspired indicator (Quariguasi Frota Neto et al., 2010) to determine the optimal decisions. An alternative LCT methodology used is the economic input-output LCA (EIO-LCA) to determine the effects of sectoral changes on the environment. On the basis of these EIO-LCAs, Alkhayyal (2019) developed a deterministic model applying orthogonal array testing, while Mohamed Abdul Ghani et al. (2017) present a MILP to run through four different scenarios of emission reduction. Another combination is mathematic programming models (Yılmaz Balaman et al., 2018) such as a deterministic multi-objective mixed integer programming model (Wang et al., 2013) or a MILP (Fahimnia et al., 2013) and scenario analysis, to optimise economic and environmental performance, e.g. under different carbon price scenarios. Finally, a tool called ModeFRONTIER ${ }^{\mathrm{TM}}$ was developed to establish the optimal closed-loop supply chain constellation, minimising costs and environmental impact through a linear MCDM approach which identifies how scenario results differ from the optimum (Bottani and Casella, 2018).

Regarding indices and indicator frameworks, AHP is proposed to identify the importance of indicators in RL (Zhou, 2012) and green SCM performance (Nie, 2016), as well as to create a performance index for reverse SCM (Butzer et al., 2017). The indicator selection can be done by expert input (Nie, 2016), or deduced from the balanced scorecard, combined with a literature review (Butzer et al., 2017; Tseng et al., 2015). AHP has also been connected with the Delphi method, employing expert consultation, to create the Green Evaluation Index based on fuzzy theory (Xu, 2009). Besides AHP, a mix of expert consultation (Olugu et al., 2011), the fuzzy Delphi method and ANP (Tseng et al., 2015) or fuzzy set theory and ANP (Ngan et al., 2019) are employed to determine the weights of the indicators.

An original combination approach by Chavez and Sharma (2018) rounds up this section. They made a simple calculation of the $\mathrm{CO}_{2}$ footprint, costs and energy consumed, and then conduct a qualitative political, economic, social, technological, legal and environmental (PESTLE) analysis to test the contextual impact on these three indicators in a manufacturing supply chain.

\section{Discussion}

The results show, on the one hand, the high diversity of approaches, and, on the other, certain patterns regarding which SA approaches are used the most, and how they are combined. These two factors hold true for both the fields of IE and CSCM, though it is evident that the two fields are represented to a different degree in the evaluation and the decision-making phase. In Section 4.2.2, IE publications are relatively less prevalent than CSCM ones, which implies that CSCM offers more ex-ante assessments and circular network design optimisation approaches. Concurrently, ex-post assessment approaches are relatively more frequently encountered in IE publications. In line with these findings, it further became apparent that most of the non-weighted SA assessment approaches indicated in Table 3 are evaluation approaches, presenting the sustainability values in the different dimensions without weighing them against one another. The weighting of sustainability dimensions through optimising for certain indicators in mathematical programming models or using MCDM models is by nature more common in decision-supporting approaches.

The most frequent ex-ante approaches are MILP models that serve to create the most eco-efficient supply chain structure, optimised according to environmental impacts and cost, as visible in Table 3. While some papers rely on literature for input values of the objective functions within the mathematical programming models, others resort to LCT methodologies. It has already been ascertained by Corona et al. (2019) that LCT and related approaches, such as LCA and SLCA, are suitable to assess circular inter-firm networks which is confirmed in both fields. While in IE, LCT methodologies are prevalent in publications focusing on the evaluation phase, in CSCM their results serve as optimisation values for the objective functions of mathematical programming models in the decision-making phase.

Another popular combination is the creation of an indicator framework which is then integrated through MCDM methods such as AHP, ANP, a consensus-oriented method such as the Delphi method or expert consultation. This is found both among IE and CSCM papers. Yet, there is a difference in how these indicators were identified. While in IE, they come from diverse sources (see e.g. Valenzuela-Venegas et al., 2016), in CSCM they are frequently derived from well-established supply chain frameworks such as the SCOR, balanced scorecard, or GRI, indicating a more businessoriented outlook. A further noteworthy observation is that customer satisfaction-related indicators are often assigned to the social realm, though they were mostly related to quality aspects and delivery times. While quality aspects can impact several social and environmental aspects, this impact is indirect and thus outside the scope of this paper.

The difference in the coverage of sustainability pillars and the depth of analysis are two further observable trends. Data inputs chosen for mathematical programming models are often limited to single indicators such as greenhouse gas emissions, costs or jobs created. Therefore, sustainability is depicted in a more reductionist manner in CSCM publications than in IE publications, where the LCT-based approaches analyse a larger number of impact categories for the same dimension. Two exceptions are the papers of Taleizadeh et al. (2019) and Pishvaee et al. (2014) with extensive analyses of different environmental impact categories and social indicators, which are however aggregated into one final indicator per dimension for the MILP model. Otherwise, as confirmed by Roos Lindgreen et al. (2020), job creation is often the only social indicator present in indicator frameworks or mathematical programming models. This shows that the focus of the SA is mainly on the employees within circular inter-firm networks, leaving aside effects on the immediate surrounding community and wider society. In the absence of more contextualised environmental impact categories, as well as social and socio-economic indicators, circular inter-firm network planning models risk having limited significance regarding the absolute (potential) impact on the immediate social and natural environment. Concurrently, the social dimension is more transparently integrated in SA approaches described in CSCM than IE literature, meaning that the weighting of the dimensions is comprehensible. If the social dimension is assessed in IE at all, SA approaches are often LCT-based and complemented with social indicators or qualitative assessments, without indicating ways to integrate the three dimensions. An intriguing finding, which is shared by Moreno-Camacho et al. (2019), is that SLCA has been mentioned only sparsely, notwithstanding its growing popularity in academia (Kühnen and Hahn, 2017). A reason for this might be that publications on SLCA mostly focus only on the social dimension and are thus outside the scope of this paper. Both the lack of social assessment approaches and their limited integration with the other sustainability dimensions in IE papers - with the notable exception of Kurup and Stehlik (2009) risk detaching the networks from their social environment and prevent IS from taking root in planned EIPs (Simboli et al., 2012).

Finally, SA approaches across both fields are highly diverse in 
terms of complexity. While some consider simple cost-benefit calculations (e.g. Chertow and Lombardi, 2005) or simplified scenario analyses (Bressanelli et al., 2019; Topi and Bilinska, 2017), other authors propose integrated mathematical programming models with LCA data, algorithms and MCDM analyses (Pishvaee et al., 2014; Sudarto et al., 2017). In that respect, an interesting framework was developed by Chardine-Baumann and BottaGenoulaz (2014) for the evaluation of sustainable SCM, because it is adaptable to the different stages of maturity in terms of sustainability practices of the circular inter-firm network. From the field of IE, Valenzuela-Venegas et al. (2016) offer hands-on advice on the selection of suitable SA indicators, but fall short in elaborating on how these indicators can be integrated. For the integration, Kurup and Stehlik (2009) and Darbari et al. (2019) amongst others necessitate the involvement of stakeholders in the weighting process, which legitimises and contextualises the indicators at once (Kühnen and Hahn, 2018). Stindt et al. (2016) also suggest making the CSCM planning level more participatory with a transdisciplinary verbal model, helping to find consensus on the purpose, scope and implementation of planning models.

\subsection{Integrated framework of SA approaches}

Based on the results and the discussion, the framework by Stindt (2017) was adapted to the approaches found in this literature review. It is essential to state that the developed framework depicted in Fig. 8 is a simplification to categorise the approaches.

The decision-supporting approaches are structured similarly to what was proposed by Stindt (2017), except that the authors opted to use the category "Heuristics" (Sasikumar and Kannan, 2009) instead of "Artificial Intelligence", due to the frequent use of multiheuristic algorithms. It is important to acknowledge that SA approaches related to heuristics were mostly used in direct connection with mathematical programming and are not applied on their own. This is captured with a bidirectional arrow in Fig. 8. The evaluation methodologies are categorised into LCT methodologies, mass balance and input-output analyses, indicator frameworks, indices, and other evaluation methodologies. Two large arrows connect the SA phases signifying the most common connections between the approaches outlined in Section 5 above. Meanwhile, the Transdisciplinary Modelling Framework (Stindt et al., 2016), the Complex Value Optimisation for Resource Recovery (Iacovidou et al., 2017a) and the Natural Step System Conditions presented in Sokka et al. (2008) neither fit the decision-supporting, nor the evaluation approaches, as they are overarching guidelines for the conduct of an entire SA process. Therefore, the decision-supporting and evaluation approaches are embedded into this encompassing layer, defining pertinent SA characteristics; the choice of the SA approaches, already constituting a value-based decision, the coverage and weighting of sustainability dimensions, the inclusion of stakeholders, the SA adaption to the local context, and the nature of data analysis (Sala et al., 2013). Concerning the latter aspect, the framework also depicts whether tools are quantitative or qualitative, which was determined based on a classification by Bocken et al. (2016) and should facilitate the approaches' applicability.

The users of the framework should read Fig. 8 from left to right. First, they need to clarify what characteristics the SA should have, by asking the questions in the top left box. Depending on whether they would like to conduct an ex-ante or an ex-post assessment, they would either opt for an evaluation method, decisionsupporting method, or a combination of both. Evaluation methods are generally more common for ex-post SAs, while for planning, optimising, and decision-making, decision-supporting approaches, usually applied as ex-ante SAs, are more suitable. Using combined approaches as indicated by the arrows might prolong data analysis but can simultaneously increase methodological rigour, especially when selecting and weighting indicators. Finally, it is central that practitioners adapt their assessment choice to the maturity of their CE practices and organisational capacities as well as resources. For example, smaller companies might find assessment approaches of qualitative a nature more suitable to their realities than larger companies would. The latter are more likely to commission external expertise to jointly develop more quantitative approaches.

\subsection{Implications for theory and practice}

The framework in Fig. 8 is meant to provide clarity to practitioners and scholars regarding the available SA approaches applicable to CE practices in circular inter-firm networks.

From a theoretical perspective, it has become apparent that SA approaches from IE and CSCM have the potential to assess the sustainability impact of CE practices in circular inter-firm networks. However, many publications do not capture the systemic nature of sustainability inherent in CE practices. The reductionist approach with which sustainability is often viewed (e.g. three optimisation values) in CSCM only captures part of the (potential) sustainability impacts and is usually limited to the perspective of companies. While CSCM research could benefit from IE's tradition of analysing environmental impacts more exhaustively, IE research would profit from integrating the social dimension more transparently. Though methodologies such as the SLCA have started to emerge, they are not yet fully integrated into the SA toolset for circular inter-firm networks, as opposed to LCA and LCC. This calls for increased stakeholder inclusion, potentially also through transdisciplinary research, which would help both fields to contextualise the SA, and look at the impacts on the community that circular inter-firm networks affect.

From a practitioner point of view, decision-makers have been given guidance on which SA approaches are available and how they are most frequently combined in literature. This can help practitioners working within circular inter-firm networks to assess whether the applied CE practices contribute positively to their sustainability performance. It is evident that some of the SA approaches require specific know-how and data which are mainly accessible for large firms. While quantitative approaches are often essential for planning circular operations, they should be contextualised with input from stakeholders to strengthen their validity and legitimacy. In contrast, a lower degree of detail might be acceptable for SAs in local networks of smaller companies, as they can partly leverage their proximity to stakeholders and their environment to observe direct impacts more qualitatively.

\section{Conclusion}

The toolbox to assess the sustainability of CE practices in circular inter-firm networks does not need to be reinvented, but rather, suitable SA approaches should be identified from existing literature. This review constitutes an important step in this direction by synthesising the academic contributions on SA in the fields of IE and CSCM over the last decades. It is the first review to explicitly connect these two fields to facilitate cross-pollination of the related SA approaches. These help to gauge the (potential) sustainability impact of CE practices and to take a subsequent decision. The results suggest that most SA approaches are applied in both the fields of IE and CSCM, though to a different degree. While SA approaches in CSCM are mainly applied as ex-ante assessments, IE-based SAs provide more detailed information ex-post, aiming to improve existing circular inter-firm networks. It was further observed that both IE and CSCM use LCT-based SA approaches frequently. 
Evaluation

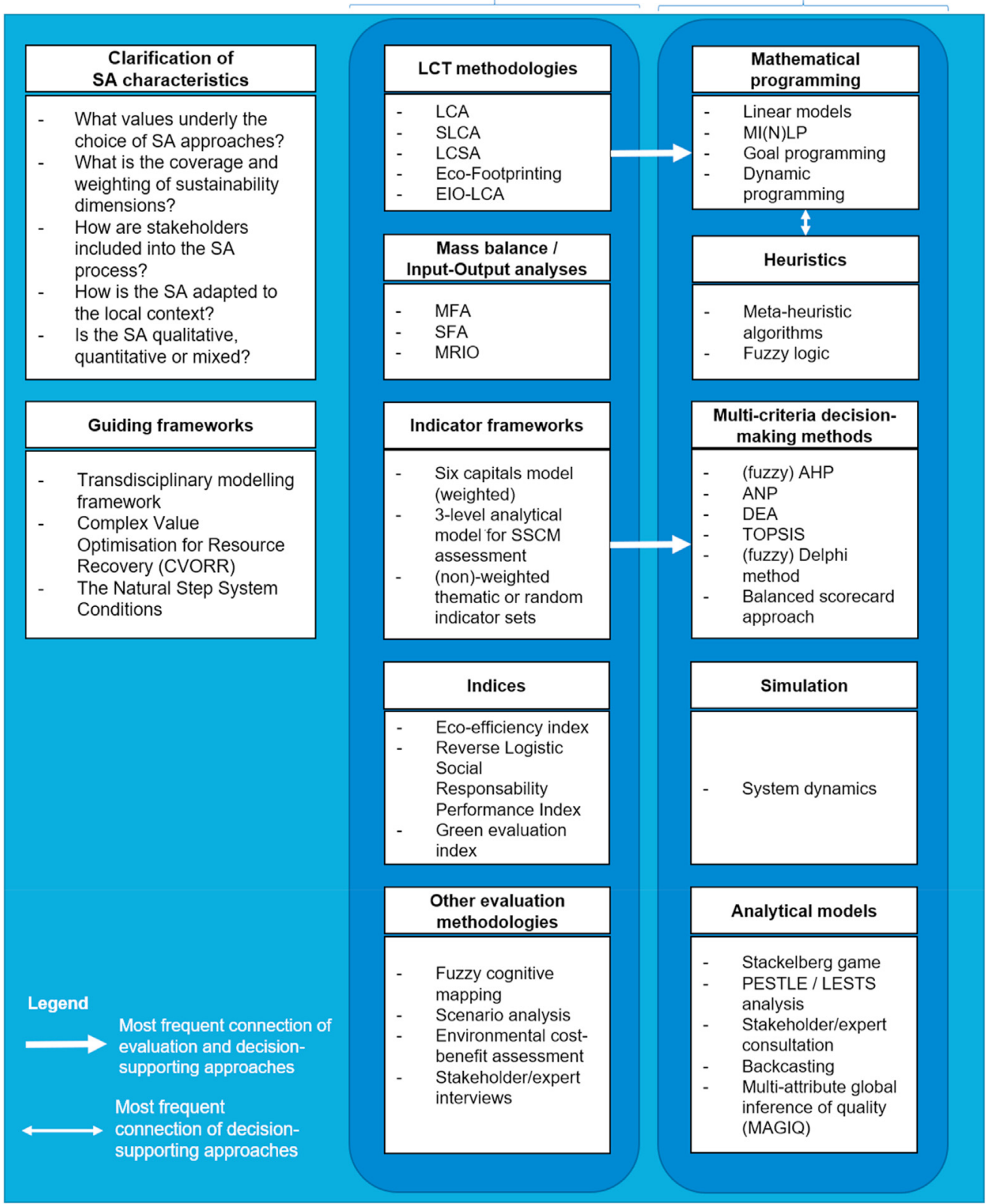

Decision-support

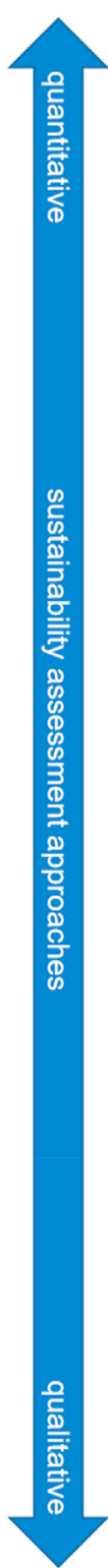

Fig. 8. Integrated SA framework for assessing CE practices in circular inter-firm networks (adapted from Stindt, 2017 and Sasikumar and Kannan, 2009).

Common combinations of the evaluation and the decisionsupporting approaches were LCT methodologies and mathematical programming, as well as indicator sets and MCDM methods. Another finding was that the environmental assessment included more impact categories in articles on IE, while CSCM publications offered more SA approaches covering all three sustainability dimensions. Furthermore, the SA approaches using mathematical programming models, mainly applied in CSCM papers, included only a small number of indicators and thus have a limited potential to depict the complexity of sustainability impacts in a particular context. As anticipated by other scholars, the social dimension was the least represented and least integrated, predominantly assessed through job creation.

Based on these findings, the authors have created an integrated framework of approaches to assess the sustainability of CE practices in circular inter-firm-networks. Given the recent focus on company and country level indicators, this framework has the potential to support both practitioners and scholars in assessing the sustainability of CE practices in a network of actors.

It is acknowledged that the keywords for the search focus predominantly on SA approaches associated with IE and CSCM, since they were found to be the most prevalent fields in CE literature. However, research on related concepts such as eco-design, performance economy, biomimicry and waste management could evidently offer additional input. Since many of these fields also apply mathematical programming, indicator frameworks, MCDM analyses, and LCT-based SA approaches, the two chosen fields seem justified, nevertheless. Furthermore, this review only touches upon network optimisation and design secondarily and not exhaustively. Therefore, future research on the optimisation of circular inter-firm 
networks for sustainability constitutes a promising avenue. Another necessary step is the identification of the actual use of SA approaches in circular inter-firm networks. Kirchherr and van Santen (2019) found that $45 \%$ of all publications on CE were conceptual and thus give limited guidance to practitioners. Therefore, it is vital to explore empirical examples of SA in all its forms. Finally, special attention should be attributed to furthering the integration and extension of the social dimension's assessment, as social aspects ultimately determine the uptake and viability of CE practices.

\section{Declaration of competing interest}

The authors declare that they have no known competing financial interests or personal relationships that could have appeared to influence the work reported in this paper.

\section{Acknowledgements}

This article constitutes part of the outcomes of the research project CRESTING (Circular Economy: Sustainability implications and guiding progress), funded by the European Union's Horizon 2020 research and innovation programme under the Marie Skłodowska-Curie grant agreement number 765198. The authors would like to thank Heather Rogers for her support in language editing the document, Tomás Ramos and Gaetano Cascini for their helpful comments on a preliminary version of this article, as well as the anonymous reviewers for their valuable feedback.

\section{Appendix A. Supplementary data}

Supplementary data to this article can be found online at https://doi.org/10.1016/j.jclepro.2020.125457.

\section{References}

Ahi, P., Jaber, M.Y., Searcy, C., 2016. A comprehensive multidimensional framework for assessing the performance of sustainable supply chains. Appl. Math. Model. 40, 10153-10166. https://doi.org/10.1016/j.apm.2016.07.001.

Ahi, P., Searcy, C., 2015a. An analysis of metrics used to measure performance in green and sustainable supply chains. J. Clean. Prod. 86, 360-377. https:// doi.org/10.1016/j.jclepro.2014.08.005.

Ahi, P., Searcy, C., 2015b. Assessing sustainability in the supply chain: a triple bottom line approach. Appl. Math. Model. 39, 2882-2896. https://doi.org/10.1016/ j.apm.2014.10.055.

Alkhayyal, B., 2019. Corporate social responsibility practices in the U.S.: using reverse supply chain network design and optimization considering carbon cost. Sustainability 11, 2097. https://doi:10.3390/su1107209.

An, X.-H., Cui, Y.-M., Qi, E.-S., 2011. Eco-efficiency evaluation of an eco-economic system - case study of Tianjin ZIYA circular-industrial park. In: Proceedings of 2011 IEEE 18th International Conference on Industrial Engineering and Engineering Management. IEEE, Piscataway, pp. 696-698. https://doi.org/10.1109/ IEEM.2011.6035251.

Anand, S., Choudhary, A.K., Singhal, P., 2019. Car ecoleasing encouraging product service system with circular economy to help environment. Indian J. Environ. Protect. 39, 352-358.

Ardente, F., Cellura, M., Brano, V.L., Mistretta, M., 2010. Life cycle assessment-driven selection of industrial ecology strategies. Integrated Environ. Assess. Manag. 6, 52-60. https://doi.org/10.1897/IEAM_2008-065.1.

Asif, F.M.A., Lieder, M., Rashid, A., 2016. Multi-method simulation based tool to evaluate economic and environmental performance of circular product systems. J. Clean. Prod. 139, 1261-1281. https://doi.org/10.1016/ j.jclepro.2016.08.122.

Bal, A., Satoglu, S.I., 2019. The use of data envelopment analysis in evaluating Pareto optimal solutions of the sustainable supply chain models. Procedia Manuf. 33, 485-492. https://doi.org/10.1016/j.promfg.2019.04.060.

Barbiroli, G., Casalicchio, G., Raggi, A., 2006. Developing a multifunctional treestructured quality index for soil management. Manag. Environ. Qual. Int. J. 17, 339-370. https://doi.org/10.1108/14777830610658746.

Batista, L., Bourlakis, M., Smart, P., Maull, R., 2018. In search of a circular supply chain archetype - a content-analysis-based literature review. Prod. Plann. Contr. 29, 438-451. https://doi.org/10.1080/09537287.2017.1343502.

Bianchini, A., Rossi, J., Pellegrini, M., 2019. Overcoming the main barriers of circular economy implementation through a new visualization tool for circular business models. Sustainability 11, 6614. https://doi.org/10.3390/su11236614.
Bocken, N., Miller, K., Evans, S., 2016. Assessing the environmental impact of new circular business models. In: Presented at the Conference "New Business Models" - Exploring a Changing View on Organizing Value Creation, 16-17 June 2016 (Toulouse).

Boix, M., Montastruc, L., Azzaro-Pantel, C., Domenech, S., 2015. Optimization methods applied to the design of eco-industrial parks: a literature review. J. Clean. Prod. 87, 303-317. https://doi.org/10.1016/j.jclepro.2014.09.032.

Introducing the social embeddedness of industrial ecology. In: Boons, F., HowardGrenville, J.A. (Eds.), 2009. The Social Embeddedness of Industrial Ecology. Elgar, Cheltenham, pp. 3-27. https://doi.org/10.4337/9781848449060.00008.

Boons, F.A.A., Baas, L.W., 1997. Types of industrial ecology: the problem of coordination. J. Clean. Prod. 5, 79-86. https://doi.org/10.1016/S0959-6526(97)000073.

Bottani, E., Casella, G., 2018. Minimization of the environmental emissions of closed-loop supply chains: a case study of returnable transport assets management. Sustainability 10, 329. https://doi.org/10.3390/su10020329.

Brandenburg, M., Govindan, K., Sarkis, J., Seuring, S., 2014. Quantitative models for sustainable supply chain management: developments and directions. Eur. J. Oper. Res. 233, 299-312. https://doi.org/10.1016/j.ejor.2013.09.032.

Brandenburg, M., Rebs, T., 2015. Sustainable supply chain management: a modeling perspective. Ann. Oper. Res. 229, 213-252. https://doi.org/10.1007/s10479-0151853-1.

Bressanelli, G., Perona, M., Saccani, N., 2019. Assessing the impacts of circular economy: a framework and an application to the washing machine industry. Int. J. Manag. Decis. Making 18, 282-308. https://doi.org/10.1504/ IJMDM.2019.100511.

Brondi, C., Cornago, S., Ballarino, A., Avai, A., Pietraroia, D., Dellepiane, U., Niero, M. 2018. Sustainability-based optimization criteria for industrial symbiosis: the Symbioptima Case. Procedia CIRP 69, 855-860. https://doi.org/10.1016/ j.procir.2017.11.026.

Bruel, A., Kronenberg, J., Troussier, N., Guillaume, B., 2019. Linking industrial ecology and ecological economics: a theoretical and empirical foundation for the circular economy. J. Ind. Ecol. 23, 12-21. https://doi.org/10.1111/jiec.12745.

Butzer, S., Schötz, S., Petroschke, M., Steinhilper, R., 2017. Development of a performance measurement system for international reverse supply chains. Procedia CIRP 61, 251-256. https://doi.org/10.1016/j.procir.2016.11.264.

Büyüközkan, G., Çifçi, G., 2013. An integrated QFD framework with multiple formatted and incomplete preferences: a sustainable supply chain application. Appl. Soft Comput. J. 13, 3931-3941. https://doi.org/10.1016/j.asoc.2013.03.014.

Calisto Friant, M., Vermeulen, W.J.V., Salomone, R., 2020. A typology of circular economy discourses: navigating the diverse visions of a contested paradigm. Resour. Conserv. Recycl. 161, 104917. https://doi.org/10.1016/ j.resconrec.2020.104917.

Cecchin, A., Salomone, R., Deutz, P., Raggi, A., Cutaia, L., 2020. Relating industrial symbiosis and circular economy to the sustainable development debate. In: Salomone, R., Cecchin, A., Deutz, P., Raggi, A., Cutaia, L. (Eds.), Industrial Symbiosis for the Circular Economy. Springer, Cham, pp. 1-25. https://doi.org/ 10.1007/978-3-030-36660-5_1.

Cervo, H., Ogé, S., Maqbool, A.S., Mendez Alva, F., Lessard, L., Bredimas, A., Ferrasse, J.-H., Van Eetvelde, G., 2019. A case study of industrial symbiosis in the Humber region using the EPOS methodology. Sustainability 11, 6940. https:// doi.org/10.3390/su11246940.

Chaabane, A., Ramudhin, A., Paquet, M., 2012. Design of sustainable supply chains under the emission trading scheme. Int. J. Prod. Econ. 135, 37-49. https:// doi.org/10.1016/j.ijpe.2010.10.025.

Chardine-Baumann, E., Botta-Genoulaz, V., 2014. A framework for sustainable performance assessment of supply chain management practices. Comput. Ind. Eng. 76, 138-147. https://doi.org/10.1016/j.cie.2014.07.029.

Chavez, R., Sharma, M., 2018. Profitability and environmental friendliness of a closed-loop supply chain for PET components: a case study of the Mexican automobile market. Resour. Conserv. Recycl. 135, 172-189. https://doi.org/ 10.1016/j.resconrec.2017.10.038.

Chertow, M.R., 2000. Industrial symbiosis: literature and taxonomy. Annu. Rev. Energy Environ. 25, 313-337. https://doi.org/10.1146/annurev.energy.25.1.313.

Chertow, M.R., Lombardi, D.R., 2005. Quantifying economic and environmental benefits of co-located firms. Environ. Sci. Technol. 39, 6535-6541. https:// doi.org/10.1021/es050050+.

Cimren, E., Fiksel, J., Posner, M.E., Sikdar, K., 2011. Material flow optimization in byproduct synergy networks. J. Ind. Ecol. 15, 315-332. https://doi.org/10.1111/ j.1530-9290.2010.00310.x.

Corona, B., Shen, L., Reike, D., Rosales Carreón, J., Worrell, E., 2019. Towards sustainable development through the circular economy - a review and critical assessment on current circularity metrics. Resour. Conserv. Recycl. 151, 104498. https://doi.org/10.1016/j.resconrec.2019.104498.

Cucchiella, F., Dadamo, I., Gastaldi, M., Koh, S.C.L., 2014. Implementation of a real option in a sustainable supply chain: an empirical study of alkaline battery recycling. Int. J. Syst. Sci. 45, 1268-1282. https://doi.org/10.1080/ 00207721.2012.761458.

Darbari, J.D., Kannan, D., Agarwal, V., Jha, P.C., 2019. Fuzzy criteria programming approach for optimising the TBL performance of closed loop supply chain network design problem. Ann. Oper. Res. 273, 693-738. https://doi.org/10.1007/ s10479-017-2701-2.

Das, K., Rao Posinasetti, N., 2015. Addressing environmental concerns in closed loop supply chain design and planning. Int. J. Prod. Econ. 163, 34-47. https://doi.org/ 10.1016/j.ijpe.2015.02.012. 
Devika, K., Jafarian, A., Nourbakhsh, V., 2014. Designing a sustainable closed-loop supply chain network based on triple bottom line approach: a comparison of metaheuristics hybridization techniques. Eur. J. Oper. Res. 235, 594-615. https://doi.org/10.1016/j.ejor.2013.12.032.

Dong, L., Liang, H., Zhang, L., Liu, Z., Gao, Z., Hu, M., 2017a. Highlighting regional ecoindustrial development: life cycle benefits of an urban industrial symbiosis and implications in China. Ecol. Model. 361, 164-176. https://doi.org/10.1016/ j.ecolmodel.2017.07.032.

Dong, L., Zhang, H., Fujita, T., Ohnishi, S., Li, H., Fujii, M., Dong, H., 2013. Environmental and economic gains of industrial symbiosis for Chinese iron/steel industry: kawasaki's experience and practice in Liuzhou and Jinan. J. Clean. Prod. 59, 226-238. https://doi.org/10.1016/j.jclepro.2013.06.048.

Dong, S., Wang, Z., Li, Y., Li, F., Li, Z., Chen, F., Cheng, H., 2017b. Assessment of comprehensive effects and optimization of a circular economy system of coal power and cement in Kongtong District, Pingliang City, Gansu Province, China. Sustainability 9, 787. https://doi.org/10.3390/su9050787.

Ehrenfeld, J.R., 2007. Would industrial ecology exist without sustainability in the background? J. Ind. Ecol. 11, 73-84. https://doi.org/10.1162/jiec.2007.1177.

Elia, V., Gnoni, M.G., Tornese, F., 2017. Measuring circular economy strategies through index methods: a critical analysis. J. Clean. Prod. 142, 2741-2751. https://doi.org/10.1016/j.jclepro.2016.10.196.

Elkington, J., 1998. Cannibals with Forks: the Triple Bottom Line of 21st Century Business. New Society Publishers, Gabriola Island, BC.

Eskandarpour, M., Dejax, P., Miemczyk, J., Péton, O., 2015. Sustainable supply chain network design: an optimization-oriented review. Omega 54, 11-32. https:// doi.org/10.1016/j.omega.2015.01.006.

Fahimnia, B., Sarkis, J., Dehghanian, F., Banihashemi, N., Rahman, S., 2013. The impact of carbon pricing on a closed-loop supply chain: an Australian case study. J. Clean. Prod. 59, 210-225. https://doi.org/10.1016/j.jclepro.2013.06.056.

Fan, W. Dong X, Wei, H., Weng B., Liang L, Xu, Z, Wang, X, Wu, F, Chen, Z, Jin, Y, Song, C., 2018. Is it true that the longer the extended industrial chain, the better the circular agriculture? A case study of circular agriculture industry company in Fuqing, Fujian. J. Clean. Prod. 189, 718-728. https://doi.org/10.1016/ j.jclepro.2018.04.119.

Farooque, M., Zhang, A., Thürer, M., Qu, T., Huisingh, D., 2019. Circular supply chain management: a definition and structured literature review. J. Clean. Prod. 228, 882-900. https://doi.org/10.1016/j.jclepro.2019.04.303.

Ferrão, P., Lorena, A., Ribeiro, P., 2015. Industrial ecology and Portugal's national waste plans. In: Clift, R., Druckman, A. (Eds.), Taking Stock of Industrial Ecology. Springer, Cham, pp. 275-289. https://doi.org/10.1007/978-3-319-20571-7 14.

Fichtner, W., Frank, M., Rentz, O., 2004. Inter-firm energy supply concepts: an option for cleaner energy production. J. Clean. Prod. 12, 891-899. https://doi.org/ 10.1016/j.jclepro.2004.02.036.

Figuière, C., Rocca, M., 2008. Un développement véritablement durable: quelle compatibilité avec le capitalisme financier ? Working paper 12/2008. Laboratoire d'économie de la production et de l'intégration internationale, Grenoble.

Fiksel, J., Bakshi, B., 2010. Industrial ecology network optimization with life cycle metrics. In: Proceedings of the 2010 IEEE International Symposium on Sustainable Systems and Technology. https://doi.org/10.1109/ISSST.2010.5507698. ISSST 2010.

Fink, A., 2014. Conducting Research Literature Reviews: from the Internet to Paper. SAGE, Thousand Oaks, California.

Fons, S., Achari, G., Ross, T., 2004. A fuzzy cognitive mapping analysis of the impacts of an eco-industrial park. J. Intell. Fuzzy Syst. 15, 75-88.

Fraccascia, L., Yazan, D.M., 2018. The supply chain implications of industrial symbiosis. Procedia Environ. Sci. Eng. Manag. 5, 61-72.

Frosch, R.A., Gallopoulos, N.E., 1989. Strategies for manufacturing. Sci. Am. 261, 144-152. https://doi.org/10.1038/scientificamerican0989-144.

Fu, Y., Zhu, Y., Lin, L., Gao, D., Ma, Y., 2019. Comparison and analysis of evaluation indexes regarding China's eco-industrial parks. In: IOP Conf. Ser. Earth Environ. Sci. Institute of Physics Publishing. https://doi.org/10.1088/1755-1315/310/5/ 052069.

Garcés-Ayerbe, C., Rivera-Torres, P., Suárez-Perales, I., Leyva-de la Hiz, D.I., 2019. Is it possible to change from a linear to a circular economy? An overview of opportunities and barriers for European small and medium-sized enterprise companies. Int. J. Environ. Res. Publ. Health 16, 851. https://doi.org/10.3390/ ijerph16050851.

Gasparatos, A., El-Haram, M., Horner, M., 2009. The argument against a reductionist approach for measuring sustainable development performance and the need for methodological pluralism. Account. Forum 33, 245-256. https://doi.org/ 10.1016/j.accfor.2008.07.006.

Geissdoerfer, M., Savaget, P., Bocken, N.M.P., Hultink, E.J., 2017. The circular economy - a new sustainability paradigm? J. Clean. Prod. 143, 757-768. https://doi.org/ 10.1016/j.jclepro.2016.12.048.

Geng, Y., Fu, J., Sarkis, J., Xue, B., 2012. Towards a national circular economy indicator system in China: an evaluation and critical analysis. J. Clean. Prod. 23, 216-224. https://doi.org/10.1016/j.jclepro.2011.07.005.

Geng, Y., Zhang, P., Côté, R.P., Fujita, T., 2009. Assessment of the national ecoindustrial park standard for promoting industrial symbiosis in China. J. Ind. Ecol. 13, 15-26. https://doi.org/10.1111/j.1530-9290.2008.00071.x.

Genovese, A., Acquaye, A.A., Figueroa, A., Koh, S.C.L., 2017. Sustainable supply chain management and the transition towards a circular economy: evidence and some applications. Omega 66, 344-357. https://doi.org/10.1016/ j.omega.2015.05.015.

Gerber, L., Fazlollahi, S., Maréchal, F., 2013. A systematic methodology for the environomic design and synthesis of energy systems combining process integration, life cycle assessment and industrial ecology. Comput. Chem. Eng. 59, 2-16. https://doi.org/10.1016/j.compchemeng.2013.05.025.

Ghisellini, P., Cialani, C., Ulgiati, S., 2016. A review on circular economy: the expected transition to a balanced interplay of environmental and economic systems. J. Clean. Prod. 114, 11-32. https://doi.org/10.1016/j.jclepro.2015.09.007.

Gibbs, D., 2009. Eco-industrial parks and industrial ecology: strategic niche or mainstream development? In: Boons, F., Howard-Grenville, J.A. (Eds.), The Social Embeddedness of Industrial Ecology. Elgar, Cheltenham, pp. 73-102. https://doi.org/10.4337/9781848449060.00013.

Gibbs, D., Deutz, P., 2007. Reflections on implementing industrial ecology through eco-industrial park development. J. Clean. Prod. 15, 1683-1695. https://doi.org/ 10.1016/j.jclepro.2007.02.003.

Giurco, D., Cohen, B., Langham, E., Warnken, M., 2011. Backcasting energy futures using industrial ecology. Technol. Forecast. Soc. Change 78, 797-818. https:// doi.org/10.1016/j.techfore.2010.09.004.

Golroudbary, S.R., Zahraee, S.M., 2015. System dynamics model for optimizing the recycling and collection of waste material in a closed-loop supply chain. Simulat. Model. Pract. Theor. 53, 88-102. https://doi.org/10.1016/ j.simpat.2015.02.001.

Govindan, K., Darbari, J.D., Agarwal, V., Jha, P.C., 2017. Fuzzy multi-objective approach for optimal selection of suppliers and transportation decisions in an eco-efficient closed loop supply chain network. J. Clean. Prod. 165, 1598-1619. https://doi.org/10.1016/j.jclepro.2017.06.180.

Govindan, K., Soleimani, H., Kannan, D., 2015. Reverse logistics and closed-loop supply chain: a comprehensive review to explore the future. Eur. J. Oper. Res. 240, 603-626. https://doi.org/10.1016/j.ejor.2014.07.012.

Guide, V.D.R., Van Wassenhove, L.N., 2009. OR forum - the evolution of closed-loop supply chain research. Oper. Res. 57, 10-18. https://doi.org/10.1287/ opre.1080.0628.

Hajiaghaei-Keshteli, M., Fathollahi Fard, A.M., 2019. Sustainable closed-loop supply chain network design with discount supposition. Neural Comput. Appl. 31, 5343-5377. https://doi.org/10.1007/s00521-018-3369-5.

Hassini, E., Surti, C., Searcy, C., 2012. A literature review and a case study of sustainable supply chains with a focus on metrics. Int. J. Prod. Econ. 140, 69-82. https://doi.org/10.1016/j.ijpe.2012.01.042.

Helander, H., Petit-Boix, A., Leipold, S., Bringezu, S., 2019. How to monitor environmental pressures of a circular economy: an assessment of indicators. J. Ind. Ecol. 1-14. https://doi.org/10.1111/jiec.12924.

Hervani, A.A., Helms, M.M., Sarkis, J., 2005. Performance measurement for green supply chain management. Benchmark Int. J. 12, 330-353. https://doi.org/ 10.1108/14635770510609015.

Homrich, A.S., Galvão, G., Abadia, L.G., Carvalho, M.M., 2018. The circular economy umbrella: trends and gaps on integrating pathways. J. Clean. Prod. 175, 525-543. https://doi.org/10.1016/j.jclepro.2017.11.064.

Howard, M., Hopkinson, P., Miemczyk, J., 2019. The regenerative supply chain: a framework for developing circular economy indicators. Int. J. Prod. Res. 57, 7300-7318. https://doi.org/10.1080/00207543.2018.1524166.

Iacovidou, E., Millward-Hopkins, J., Busch, J., Purnell, P., Velis, C.A., Hahladakis, J.N., Zwirner, O., Brown, A., 2017a. A pathway to circular economy: developing a conceptual framework for complex value assessment of resources recovered from waste. J. Clean. Prod. 168, 1279-1288. https://doi.org/10.1016/ j.jclepro.2017.09.002.

Iacovidou, E., Velis, C.A., Purnell, P., Zwirner, O., Brown, A., Hahladakis, J., MillwardHopkins, J., Williams, P.T., 2017b. Metrics for optimising the multi-dimensional value of resources recovered from waste in a circular economy: a critical review. J. Clean. Prod. 166, 910-938. https://doi.org/10.1016/j.jclepro.2017.07.100.

Jacobsen, N.B., 2006. Industrial Symbiosis in Kalundborg, Denmark: a quantitative assessment of economic and environmental aspects. J. Ind. Ecol. 10, 239-255. https://doi.org/10.1162/108819806775545411.

Jain, S., Jain, N.K., Metri, B., 2018. Strategic framework towards measuring a circular supply chain management. Benchmark Int. J. 25, 3238-3252. https://doi.org/ 10.1108/BIJ-11-2017-0304.

Jiao, Z., Ran, L., Zhang, Y., Li, Z., Zhang, W., 2018. Data-driven approaches to integrated closed-loop sustainable supply chain design under multi-uncertainties. J. Clean. Prod. 185, 105-127. https://doi.org/10.1016/j.jclepro.2018.02.255.

Jindal, A., Sangwan, K.S., 2017. Multi-objective fuzzy mathematical modelling of closed-loop supply chain considering economical and environmental factors. Ann. Oper. Res. 257, 95-120. https://doi.org/10.1007/s10479-016-2219-z.

Johari, M., Hosseini-Motlagh, S.-M., 2019. Coordination of social welfare, collecting, recycling and pricing decisions in a competitive sustainable closed-loop supply chain: a case for lead-acid battery. Ann. Oper. Res. https://doi.org/10.1007/ s10479-019-03292-1.

Jung, S., Dodbiba, G., Chae, S.H., Fujita, T., 2013. A novel approach for evaluating the performance of eco-industrial park pilot projects. J. Clean. Prod. 39, 50-59. https://doi.org/10.1016/j.jclepro.2012.08.030.

Kafa, N., Hani, Y., El Mhamedi, A., 2013. Sustainability performance measurement for green supply chain management. IFAC Proc. 46, 71-78. https://doi.org/ 10.3182/20130911-3-BR-3021.00050.

Kazancoglu, Y., Kazancoglu, I., Sagnak, M., 2018. A new holistic conceptual framework for green supply chain management performance assessment based on circular economy. J. Clean. Prod. 195, 1282-1299. https://doi.org/10.1016/ j.jclepro.2018.06.015.

Kirchherr, J., Reike, D., Hekkert, M., 2017. Conceptualizing the circular economy: an analysis of 114 definitions. Resour. Conserv. Recycl. 127, 221-232. https:// 
doi.org/10.1016/j.resconrec.2017.09.005

Kirchherr, J., van Santen, R., 2019. Research on the circular economy: a critique of the field. Resour. Conserv. Recycl. 151, 104480. https://doi.org/10.1016/ j.resconrec.2019.104480.

Korhonen, J., 2002. Two paths to industrial ecology: applying the product-based and geographical approaches. J. Environ. Plann. Manag. 45, 39-57. https:// doi.org/10.1080/09640560120100187.

Korhonen, J., Honkasalo, A., Seppälä, J., 2018. Circular economy: the concept and its limitations. Ecol. Econ. 143, 37-46. https://doi.org/10.1016/ i.ecolecon.2017.06.041.

Kravchenko, M., Pigosso, D.C.A., McAloone, T.C., 2019. Towards the ex-ante sustainability screening of circular economy initiatives in manufacturing companies: consolidation of leading sustainability-related performance indicators. J. Clean. Prod. 241, 118318. https://doi.org/10.1016/j.jclepro.2019.118318.

Kristensen, H.S., Mosgaard, M.A., 2020. A review of micro level indicators for a circular economy - moving away from the three dimensions of sustainability? J. Clean. Prod. 243, 118531. https://doi.org/10.1016/j.jclepro.2019.118531.

Kühnen, M., Hahn, R., 2018. Systemic social performance measurement: systematic literature review and explanations on the academic status quo from a product life-cycle perspective. J. Clean. Prod. 205, 690-705. https://doi.org/10.1016/ j.jclepro.2018.08.201.

Kühnen, M., Hahn, R., 2017. Indicators in social life cycle assessment: a review of frameworks, theories, and empirical experience. J. Ind. Ecol. 21, 1547-1565. https://doi.org/10.1111/jiec.12663.

Kurup, B., Stehlik, D., 2009. Towards a model to assess the sustainability implications of industrial symbiosis in eco-industrial parks. Prog. Ind. Ecol. Int. J. 6, 103-119. https://doi.org/101504/PIE 2009.029077.

Kuznetsova, E., Zio, E., Farel, R., 2016. A methodological framework for ecoindustrial park design and optimization. J. Clean. Prod. 126, 308-324. https:// doi.org/10.1016/j.jclepro.2016.03.025.

Li, C., 2013. An integrated approach to evaluating the production system in closedloop supply chains. Int. J. Prod. Res. 51, 4045-4069. https://doi.org/10.1080/ 00207543.2013 .774467$.

Martin, M., Harris, S., 2018. Prospecting the sustainability implications of an emerging industrial symbiosis network. Resour. Conserv. Recycl. 138, 246-256. https://doi.org/10.1016/j.resconrec.2018.07.026.

Marvuglia, A., Rugani, B., Ulgiati, S., Santagata, R., Benetto, E., 2018. Emergy-based indicators to measure circularity: promises and problems. Polityka energetyczna - Energy Pol. J. 21, 179-196. https://doi.org/10.24425/124510.

Masi, D., Day, S., Godsell, J., 2017. Supply chain configurations in the circular economy: a systematic literature review. Sustainability 9, 1602. https://doi.org/ $10.3390 /$ su9091602.

Mehrjerdi, Y.Z., Lotfi, R., 2019. Development of a mathematical model for sustainable closed-loop supply chain with efficiency and resilience systematic framework. Int. J. Supply Oper. Manag. 6, 360-388. https://doi.org/10.22034/2019.4.6.

Metta, H., Badurdeen, F., 2011. Environmental and societal assessments for sustainable product and supply chain design. In: Doolen, T., Van Aken, E. (Eds.), Proceedings of the 2011 Industrial Engineering Research Conference. Reno.

Michelsen, O., Fet, A.M., 2010. Using eco-efficiency in sustainable supply chain management: a case study of furniture production. Clean Technol. Environ. Policy 12, 561-570. https://doi.org/10.1007/s10098-009-0266-8.

Mirmohammadi, S.H., Sahraeian, R., 2018. A novel sustainable closed-loop supply chain network design by considering routing and quality of products. Int. J. Eng. Transact. B: Appl. 31, 1918-1928. https://doi.org/10.5829/ije.2018.31.11b.16.

Modak, N.M., Kazemi, N., Cárdenas-Barrón, L.E., 2019. Investigating structure of a two-echelon closed-loop supply chain using social work donation as a corporate social responsibility practice. Int. J. Prod. Econ. 207, 19-33. https://doi.org/ 10.1016/j.ijpe.2018.10.009.

Mohajeri, A., Fallah, M., 2016. A carbon footprint-based closed-loop supply chain model under uncertainty with risk analysis: a case study. Transport. Res. Transport Environ. 48, 425-450. https://doi.org/10.1016/j.trd.2015.09.001.

Mohamed Abdul Ghani, N.M.A., Egilmez, G., Kucukvar, M., Khurrum, M.K., Bhutta, S., 2017. From green buildings to green supply chains: an integrated input-output life cycle assessment and optimization framework for carbon footprint reduction policy making. Manag. Environ. Qual. Int. J. 28, 532-548. https://doi.org/ 10.1108/MEQ-12-2015-0211.

Moher, D., Liberati, A., Tetzlaff, J., Altman, D.G., 2009. Preferred reporting items for systematic reviews and meta-analyses: the PRISMA statement. PLoS Med. 6, e1000097. https://doi:10.1371/journal.pmed1000097.

Mongeon, P., Paul-Hus, A., 2016. The journal coverage of Web of Science and Scopus: a comparative analysis. Scientometrics 106, 213-228. https://doi.org/ $10.1007 /$ s 11192-015-1765-5.

Moraga, G., Huysveld, S., Mathieux, F., Blengini, G.A., Alaerts, L., Van Acker, K., de Meester, S., Dewulf, J., 2019. Circular economy indicators: what do they measure? Resour. Conserv. Recycl. 146, 452-461. https://doi.org/10.1016/ j.resconrec.2019.03.045.

Moreno-Camacho, C.A., Montoya-Torres, J.R., Jaegler, A., Gondran, N., 2019. Sustainability metrics for real case applications of the supply chain network design problem: a systematic literature review. J. Clean. Prod. 231, 600-618. https:// doi.org/10.1016/j.jclepro.2019.05.278.

Mota, B., Gomes, M.I., Carvalho, A., Barbosa-Povoa, A.P., 2018. Sustainable supply chains: an integrated modeling approach under uncertainty. Omega 77, 32-57. https://doi.org/10.1016/j.omega.2017.05.006.

Mubin, A., 2016. Development of sustainable performance measurement system for electronic and plastics industrial cluster based industrial symbiosis scenario in the industrial estate. In: Proceedings of the International Conference on Industrial Engineering and Operations Management. Kuala Lumpur pp. $1122-1128$.

Murray, A., Skene, K., Haynes, K., 2015. The circular economy: an interdisciplinary exploration of the concept and application in a global context. J. Bus. Ethics 140 369-380. https://doi.org/10.1007/s10551-015-2693-2.

Ngan, S.L., How, B.S., Teng, S.Y., Promentilla, M.A.B., Yatim, P., Er, A.C., Lam, H.L., 2019. Prioritization of sustainability indicators for promoting the circular economy: the case of developing countries. Renew. Sustain. Energy Rev. 111, 314-331. https://doi.org/10.1016/j.rser.2019.05.001.

Nidhi, M.B., Madhusudanan Pillai, V., 2019. Product disposal penalty: analysing carbon sensitive sustainable supply chains. Comput. Ind. Eng. 128, 8-23. https://doi.org/10.1016/j.cie.2018.11.059.

Nie, X., 2016. Dynamic assessment of business performance in green supply chain based on analytic hierarchy process method. Int. J. Secur. Appl. 10, 185-196. https://doi.org/10.14257/ijsia.2016.10.2.17.

Niero, M., Hauschild, M.Z., 2017. Closing the loop for packaging: finding a framework to operationalize circular economy strategies. Procedia CIRP 61, 685-690. https://doi.org/10.1016/j.procir.2016.11.209.

Nikolaou, I.E., Evangelinos, K.I., Allan, S., 2013. A reverse logistics social responsibility evaluation framework based on the triple bottom line approach. J. Clean. Prod. 56, 173-184. https://doi.org/10.1016/j.jclepro.2011.12.009.

Nobari, A., Kheirkhah, A., 2018. Integrated and dynamic design of sustainable closed-loop supply chain network considering pricing. Sci. Iran. 25, 410-430. https://doi.org/10.24200/sci.2017.4411.

Olugu, E.U., Wong, K.Y., Shaharoun, A.M., 2011. Development of key performance measures for the automobile green supply chain. Resour. Conserv. Recycl. 55, 567-579. https://doi.org/10.1016/j.resconrec.2010.06.003.

Pakarinen, S., Mattila, T., Melanen, M., Nissinen, A., Sokka, L., 2010. Sustainability and industrial symbiosis -the evolution of a Finnish forest industry complex Resour. Conserv. Recycl. 54, 1393-1404. https://doi.org/10.1016/ j.resconrec.2010.05.015.

Park, H.-S., Behera, S.K., 2014. Methodological aspects of applying eco-efficiency indicators to industrial symbiosis networks. J. Clean. Prod. 64, 478-485. https://doi.org/10.1016/j.jclepro.2013.08.032.

Pishvaee, M.S., Razmi, J., Torabi, S.A., 2014. An accelerated Benders decomposition algorithm for sustainable supply chain network design under uncertainty: a case study of medical needle and syringe supply chain. Transport. Res. E Logist. Transport. Rev. 67, 14-38. https://doi.org/10.1016/j.tre.2014.04.001.

Pourjavad, E., Mayorga, R.V., 2018. Optimization of a sustainable closed loop supply chain network design under uncertainty using multi-objective evolutionary algorithms. Adv. Prod. Eng. Manag. 13, 216-228. https://doi.org/10.14743/ apem2018.2.286.

Pourjavad, E., Mayorga, R.V., 2019. Multi-objective fuzzy programming of closedloop supply chain considering sustainable measures. Int. J. Fuzzy Syst. 21, 655-673. https://doi.org/10.1007/s40815-018-0551-y.

President's Council on Sustainable Development, 1997. In: Eco-Industrial Park Workshop Proceedings, Oct. 17-18, 1996. Cape Charles, VA.

Quariguasi Frota Neto, J., Bloemhof-Ruwaard, J.M., van Nunen, J.A.E.E., van Heck, E. 2008. Designing and evaluating sustainable logistics networks. Int. J. Prod. Econ. 111, 195-208. https://doi.org/10.1016/j.ijpe.2006.10.014.

Quariguasi Frota Neto, J., Walther, G., Bloemhof, J., Van Nunen, J.A.E.E., Spengler, T. 2010. From closed-loop to sustainable supply chains: the WEEE case. Int. J. Prod. Res. 48, 4463-4481. https://doi.org/10.1080/00207540902906151.

Reike, D., Vermeulen, W.J.V., Witjes, S., 2018. The circular economy: new or refurbished as CE 3.0? - exploring controversies in the conceptualization of the circular economy through a focus on history and resource value retention options. Resour. Conserv. Recycl. 135, 246-264. https://doi.org/10.1016/ j.resconrec.2017.08.027.

Rezaei, S., Kheirkhah, A., 2018. A comprehensive approach in designing a sustainable closed-loop supply chain network using cross-docking operations. Comput. Math. Organ. Theor. 24, 51-98. https://doi.org/10.1007/s10588-017-9247-3.

Rogers, D.S., Tibben-Lembke, R.S., 1999. Going Backwards: Reverse Logistics Trends and Practices. University of Nevada, Reno.

Roos Lindgreen, E., Salomone, R., Reyes, T., 2020. A critical review of academic approaches, methods and tools to assess circular economy at the micro level Sustainability 12, 4973. https://doi.org/10.3390/su12124973.

Saavedra, Y.M.B., Iritani, D.R., Pavan, A.L.R., Ometto, A.R., 2018. Theoretical contribution of industrial ecology to circular economy. J. Clean. Prod. 170, 1514-1522. https://doi.org/10.1016/j.jclepro.2017.09.260.

Saidani, M., Kendall, A., Yannou, B., Leroy, Y., Cluzel, F., 2019a. Closing the loop on platinum from catalytic converters: contributions from material flow analysis and circularity indicators. J. Ind. Ecol. 23, 1143-1158. https://doi.org/10.1111/ jiec.12852.

Saidani, M., Yannou, B., Leroy, Y., Cluzel, F., Kendall, A., 2019b. A taxonomy of circular economy indicators. J. Clean. Prod. 207, 542-559. https://doi.org/10.1016/ j.jclepro.2018.10.014.

Saidani, M., Yannou, B., Leroy, Y., Cluzel, F., Saidani, M., Yannou, B., Leroy, Y., Cluzel, F., 2017. How to assess product performance in the circular economy? Proposed requirements for the design of a circularity measurement framework. Recycling 2, 6. https://doi.org/10.3390/recycling2010006.

Sala, S., Farioli, F., Zamagni, A., 2013. Progress in sustainability science: lessons learnt from current methodologies for sustainability assessment: Part 1. Int. J. Life Cycle Assess. 18, 1653-1672. https://doi.org/10.1007/s11367-012-0508-6.

Santos, V.E.N., Magrini, A., 2018. Biorefining and industrial symbiosis: a proposal for 
regional development in Brazil. J. Clean. Prod. 177, 19-33. https://doi.org/ 10.1016/j.jclepro.2017.12.107.

Sarkar, B., Ullah, M., Kim, N., 2017. Environmental and economic assessment of closed-loop supply chain with remanufacturing and returnable transport items. Comput. Ind. Eng. 111, 148-163. https://doi.org/10.1016/j.cie.2017.07.003.

Sasikumar, P., Kannan, G., 2009. Issues in reverse supply chain, part III: classification and simple analysis. Int. J. Sustain. Eng. 2, 2-27. https://doi.org/10.1080/ 19397030802673374.

Seager, T.P., Theis, T.L., 2004. A taxonomy of metrics for testing the industrial ecology hypotheses and application to design of freezer insulation. J. Clean. Prod. 12, 865-875. https://doi.org/10.1016/j.jclepro.2004.02.032.

Sehnem, S., Vazquez-Brust, D., Pereira, S.C.F., Campos, L.M.S., 2019. Circular economy: benefits, impacts and overlapping. Suppl. Chain Manag. Int. J. 24, 784-804. https://doi.org/10.1108/SCM-06-2018-0213.

Sgarbossa, F., Russo, I., 2017. A proactive model in sustainable food supply chain: insight from a case study. Int. J. Prod. Econ. 183, 596-606. https://doi.org/ 10.1016/j.ijpe.2016.07.022.

Simboli, A., Taddeo, R., Morgante, A., 2012. Place-based approaches to industrial ecology. Considerations about the application in long-standing industrial clusters. In: Ioppolo, G. (Ed.), Environment and Energy. Franco Angeli, Milan, pp. 177-189.

Sokka, L., Melanen, M., Nissinen, A., 2008. How can the sustainability of industrial symbioses be measured? Prog. Ind. Ecol. Int. J. 5, 518-535. https://doi.org/ 10.1504/PIE.2008.023414

Stindt, D., 2017. A generic planning approach for sustainable supply chain management - how to integrate concepts and methods to address the issues of sustainability? J. Clean. Prod. 153, 146-163. https://doi.org/10.1016/ j.jclepro.2017.03.126.

Stindt, D., Sahamie, R., Nuss, C., Tuma, A., 2016. How transdisciplinarity can help to improve operations research on sustainable supply chains - a transdisciplinary modeling framework. J. Bus. Logist. 37, 113-131. https://doi.org/10.1111/ jbl.12127.

Strazza, C., Magrassi, F., Gallo, M., Del Borghi, A., 2015. Life cycle assessment from food to food: a case study of circular economy from cruise ships to aquaculture. Sustain. Prod. Consum. 2, 40-51. https://doi.org/10.1016/j.spc.2015.06.004.

Suárez-Eiroa, B., Fernández, E., Méndez-Martínez, G., Soto-Oñate, D., 2019. Operational principles of circular economy for sustainable development: linking theory and practice. J. Clean. Prod. 214, 952-961. https://doi.org/10.1016/ j.jclepro.2018.12.271.

Sudarto, S., Takahashi, K., Morikawa, K., 2017. Reprint "Efficient flexible long-term capacity planning for optimal sustainability dimensions performance of reverse logistics social responsibility: a system dynamics approach. Int. J. Prod. Econ. 190, 45-59. https://doi.org/10.1016/j.ijpe.2017.06.017.

Sydow, J., Windeler, A., 1998. Organizing and evaluating interfirm networks: a structurationist perspective on network processes and effectiveness. Organ. Sci. 9, 265-284. https://doi.org/10.1287/orsc.9.3.265.

Taleizadeh, A.A., Haghighi, F., Niaki, S.T.A., 2019. Modeling and solving a sustainable closed loop supply chain problem with pricing decisions and discounts on returned products. J. Clean. Prod. 207, 163-181. https://doi.org/10.1016/ j.jclepro.2018.09.198.

Tang, Y., Li, J., 2010. Material flow analysis on venous industrial park - taking Tianjin Ziya Circular Economy Park for example. In: Proceedings of 2010 IEEE 17th International Conference on Industrial Engineering and Engineering Management. IE and EM2010, Xiamen, pp. 1828-1831. https://doi.org/10.1109/ ICIEEM.2010.5645913.

Tarne, P., Traverso, M., Finkbeiner, M., 2017. Review of life cycle sustainability assessment and potential for its adoption at an automotive company. Sustainability 9, 670. https://doi.org/10.3390/su9040670.

Taticchi, P., Garengo, P., Nudurupati, S.S., Tonelli, F., Pasqualino, R., 2015. A review of decision-support tools and performance measurement and sustainable supply chain management. Int. J. Prod. Res. 53, 6473-6494. https://doi.org/10.1080/ 00207543.2014 .939239$.

Tavakkoli Moghaddam, S., Javadi, M., Hadji Molana, S.M., 2019. A reverse logistics chain mathematical model for a sustainable production system of perishable goods based on demand optimization. J. Ind. Eng. Int. 15, 709-721. https:// doi.org/10.1007/s40092-018-0287-1.

Topi, C., Bilinska, M., 2017. The economic case for the circular economy: from food waste to resource. In: Morone, P., Papendiek, F., Tartiu, V. (Eds.), Food Waste Reduction and Valorisation: Sustainability Assessment and Policy Analysis. Springer, Cham, pp. 25-41. https://doi.org/10.1007/978-3-319-50088-1_3.

Trokanas, N., Cecelja, F., Raafat, T., 2015. Semantic approach for pre-assessment of environmental indicators in industrial symbiosis. J. Clean. Prod. 96, 349-361. https://doi.org/10.1016/j.jclepro.2013.12.046.

Tseng, M., Lim, M., Wong, W.P., 2015. Sustainable supply chain management: a closed-loop network hierarchical approach. Ind. Manag. Data Syst. 115, 436-461. https://doi.org/10.1108/IMDS-10-2014-0319.

UN General Assembly, 2015. Transforming Our World: the 2030 Agenda for Sustainable Development, A/RES/70/1. URL. https://www.refworld.org/docid/ 57b6e3e44.html. (Accessed 30 December 2019).

Urbinati, A., Chiaroni, D., Chiesa, V., 2017. Towards a new taxonomy of circula economy business models. J. Clean. Prod. 168, 487-498. https://doi.org/10.1016/ j.jclepro.2017.09.047.

Valenzuela-Venegas, G., Salgado, J.C., Díaz-Alvarado, F.A., 2016. Sustainability indicators for the assessment of eco-industrial parks: classification and criteria for selection. J. Clean. Prod. 133, 99-116. https://doi.org/10.1016/ j.jclepro.2016.05.113.

Vermeulen, W.J.V., 2018. Substantiating the rough consensus on the concept of sustainable development as a point of departure for indicator development. In: Bell, S., Morse, S. (Eds.), Routledge Handbook of Sustainability Indicators Routledge Handbooks Online, pp. 59-92. https://doi.org/10.4324 9781315561103-4.

Verstraeten-Jochemsen, J., Keijzer, E., van Harmelen, T., Kootstra, L., Kuindersma, P., Koch, R., 2018. IMPACT: a tool for R\&D management of circular economy innovations. Procedia CIRP 69, 769-774. https://doi.org/10.1016/ j.procir.2017.11.096.

Walker, A., Raggi, A., Simboli, A., Vermeulen, W.J.V., 2019. Measuring the sustainability impact of circular economy practices: comparing academia and practice. Aligning the methodological framework with a fuzzy concept. In: The 25th International Sustainable Development Research Society Conference (ISDRS 2019) - Book of Papers,. Nanjing University, Nanjing, pp. 450-463.

Wang, G., Gunasekaran, A., 2015. Modeling and analysis of sustainable supply chain dynamics. Ann. Oper. Res. 250, 521-536. https://doi.org/10.1007/s10479-0151860-2.

Wang, L.C., Chen, T.L., Chen, Y.Y., Chen, Y.W., Wang, A., 2013. Closed-loop sustainable supply chain design under uncertainties. Lect. Notes Mech. Eng. 7, 799-812. https://doi.org/10.1007/978-3-319-00557-7_66.

Wen, Z., Meng, X., 2015. Quantitative assessment of industrial symbiosis for the promotion of circular economy: a case study of the printed circuit boards industry in China's Suzhou New District. J. Clean. Prod. 90, 211-219. https:// doi.org/10.1016/j.jclepro.2014.03.041.

Wenbo, L., 2011. Comprehensive evaluation research on circular economic performance of eco-industrial parks. Energy Procedia 5, 1682-1688. https://doi.org/ 10.1016/j.egypro.2011.03.287.

White, R.M., 1994. Preface. In: Allenby, B.R., Richards, D.J. (Eds.), The Greening of Industrial Ecosystems. National Academy Press, Washington, D.C, pp. i-iv. https://doi.org/10.17226/2129.

World Commission on Environment and Development (Ed.), 1987. Our Common Future. Oxford University Press, Oxford.

Xu, F., Xiang, N., Tian, J., Chen, L., 2017. 3Es-based optimization simulation approach to support the development of an eco-industrial park with planning towards sustainability: a case study in Wuhu, China. J. Clean. Prod. 164, 476-484. https://doi.org/10.1016/j.jclepro.2017.06.192.

$\mathrm{Xu}, \mathrm{J} ., 2009$. Model of cluster green supply chain performance evaluation based on circular economy. In: Proceedings of 2nd International Conference on Intelligent Computing Technology and Automation. ICICTA, pp. 941-944. https:// doi.org/10.1109/ICICTA.2009.692, 2009.

Xu, X., Ma, Z., Chen, Y., Gu, X., Liu, Q., Wang, Y., Sun, M., Chang, D., 2018. Circular economy pattern of livestock manure management in Longyou, China. J. Mater. Cycles Waste Manag. 20, 1050-1062. https://doi.org/10.1007/s10163-017-06674.

Yılmaz Balaman, Ş., Wright, D.G., Scott, J., Matopoulos, A., 2018. Network design and technology management for waste to energy production: an integrated optimization framework under the principles of circular economy. Energy 143, 911-933. https://doi.org/10.1016/j.energy.2017.11.058.

Zhang, X., Ma, F., Wang, L., 2013. Application of life cycle assessment in agricultural circular economy. Appl. Mech. Mater. 261-262, 1086-1091. https://doi.org/10. 4028/www.scientific.net/AMM.260-261.1086.

Zhao, H., Guo, S., Zhao, H., 2018. Comprehensive benefit evaluation of eco-industrial parks by employing the best-worst method based on circular economy and sustainability. Environ. Dev. Sustain. 20, 1229-1253. https://doi.org/10.1007/ s10668-017-9936-6.

Zhao, H., Zhao, H., Guo, S., 2017. Evaluating the comprehensive benefit of ecoindustrial parks by employing multi-criteria decision making approach for circular economy. J. Clean. Prod. 142, 2262-2276. https://doi.org/10.1016/ j.jclepro.2016.11.041.

Zhou, Z., 2012. Research on green degree evaluation of reverse logistics system based on fuzzy comprehensive evaluation method. Adv. Mater. Res. 524-527, 3750-3753. https://doi.org/10.4028/www.scientific.net/AMR.524-527.3750. 